\title{
Analog/RF Performance Analysis of a-ITZO Thin Film Transistor
}

\author{
Neeraj Jain $^{1,2} \oplus \cdot$ Kunal Singh $^{3} \cdot$ Shashi Kant Sharma ${ }^{4} \cdot$ Renu Kumawat $^{1}$
}

Received: 2 September 2021 / Accepted: 8 December 2021 / Published online: 12 February 2022

(c) Springer Nature B.V. 2022

\begin{abstract}
This work reports RF and analog performance analysis of an amorphous Indium Tin Zinc Oxide thin film transistor. The various parameters affecting the performance of a-ITZO TFT like drain current, drain conductance, output resistance, transconductance, transconductance generation factor, early voltage, intrinsic gain, capacitances, cut off frequency, maximum frequency of oscillation, transconductance frequency product, gain frequency product, gain bandwidth product and gain transconductance frequency product have been closely examined. The device is further analyzed to investigate the impact of variation in physical parameters viz. dielectric material, dielectric thickness $(D t)$ and temperature $(\mathrm{T})$ on the RF/Analog performance. Use of high- $k$ dielectric material in the simulated structure has resulted in low subthreshold slope (SS) of $0.62 \mathrm{~V} /$ decade, On voltage $(V o n)$ of $-0.29 \mathrm{~V}$, Ion/Ioff ratio of $\sim 10^{9}$, intrinsic gain $\left(\mathrm{A}_{\mathrm{v}}\right)$ of $104.5 \mathrm{~dB}$ and gain frequency product (GFP) of $1.86 \mathrm{GHz}$. The best results for dielectric thickness variation are obtained for $\mathrm{D}_{\mathrm{t}}$ of $150 \mathrm{~nm}$ with SS of $0.22 \mathrm{~V} /$ decade, Von of $-0.26 \mathrm{~V}$, Ion/Ioff of $\sim 10^{10}, \mathrm{~A}_{\mathrm{v}}$ of $175.69 \mathrm{~dB}$ and GFP of $2.39 \mathrm{GHz}$. In order to investigate device thermal reliability and stability, temperature analysis has also been done. To demonstrate the circuit level implementation of the simulated structure, a resistive load inverter circuit is simulated and analyzed for different variations (high- $k, D t$ and $\mathrm{T})$. It has also been concluded that TFT with high- $k$ material or thinner dielectric at $\mathrm{T}=300 \mathrm{~K}$ provides best performance. This analysis confirms the potential of a-ITZO TFTs to realize high performance analog/RF circuits.
\end{abstract}

Keywords Analog/RF performance $\cdot$ a-ITZO TFTs $\cdot$ Dielectric material $\cdot$ Dielectric thickness $\cdot$ TCAD

\section{Introduction}

In recent years, thin film transistors have drawn a significant attention of researchers as it has become the backbone of thin film electronics industry. A CAGR of $17.34 \%$ is expected to register for TFT market during 2021-2026 [1]. TFT is used as a pixel switching element in LED or flat panel displays [2-4].

Neeraj Jain

neerajengi24@gmail.com

1 Department of Electronics and Communication Engineering, Manipal University Jaipur, Rajasthan 303007, India

2 Department of Electronics and Communication Engineering, Swami Keshvanand Institute of Technology, Management and Gramothan, Jaipur, Rajasthan 302017, India

3 Department of Electronics and Communication Engineering, National Institute of Technology, Jamshedpur, Jharkhand 831014, India

4 Department of Electronics and Communication Engineering, Indian Institute of Information Technology Ranchi, 834010 Jharkhand, India
The major outlook of display industry is to produce large area and high-resolution displays. Therefore, there is an immediate need to improve the performance of TFTs. TFT is a special type of transistor which has a supporting substrate over which a layer of dielectric, semiconductor and contacts are deposited [5]. The material used as channel layer are A-Si, Poly Si, Semiconducting Metal Oxides (SMO's) etc. Use of A-Si and Poly-Si for large and high-resolution display is now becoming unacceptable because of its low mobility, high processing temperature and inferior electrical properties [6]. Considering these limitations, semiconductor oxide materials like $\mathrm{ZnO}$ [7], $\mathrm{SnO}_{2}$ [8], GaZnO [9], IGZO [10] etc. are seen as a replacement to A-Si and Poly-Si. Among all semiconductor oxide materials, $\mathrm{ZnO}$ has drawn a significant attention of researchers because of its large band gap, low cost, good transparency, appreciable mobility, abundance in nature and high excitation energy [11]. However, Chung et al. [12] reported that $\mathrm{ZnO}$ has many grain boundaries which limit its use in large and high-resolution displays. This obstacle was resolved by doping $\mathrm{ZnO}$ with metals like In [13], $\mathrm{Al}$ [14], Tin [15], $\mathrm{Mg}$ [16] etc. to make amorphous oxide semiconductors (AOS) with no grain boundaries. As 
reported by Lee et al. [17], IGZO as AOS in channel layer of TFT provides high electric mobility as well as high optical transmittance. Nomura et al. [18] reported first IGZO TFT at room temperature and suggested that IGZO can be used as a potential material for future electronic devices. Yabuta et al. [19] grown IGZO as channel material for TFT with mobility $\left(\mu_{f e}\right)$ of the order of $\sim 10$ and $I_{\text {or }} I_{\text {off }}$ ratio of the order of $\sim 10^{8}$. However, this high mobility and stability is still not sufficient for next generation displays which require $\mu_{f e}$ of the order of $\sim$ 20. Wang et al. [20] proposed a-ITZO as an alternative of IGZO with high $\mu_{f e}(\sim 44)$ and good stability. Zhong et al. [21] reported that ITZO is a potential TFT channel material as it offers high mobility of $\sim 19 \mathrm{~cm}^{2} \mathrm{~V}^{-1} \mathrm{~s}^{-1}$, and subthreshold swing of $\sim 0.6 \mathrm{~V}$. Based upon the past literature, it can be concluded that a-ITZO has all potential properties that makes it a potential material for TFTs.

To investigate the applicability of a-ITZO as channel layer in TFTs, a simulation study using ATLAS tool [22] from Silvaco TCAD have been reported in this work. To demonstrate the use of a-ITZO TFT in Analog/RF application, different $\mathrm{RF} /$ Analog parameters have been studied. To the best of our knowledge, this kind of investigations have not been reported in literature for TFTs. Furthermore, it has also been seen that high density analog and RF application are facing challenges in the attainment of higher device performance like low power and high frequency of operation. Different methods like scaling the geometric dimensions, material changes and temperature variability [23-27] can effectively make the TFTs to work at low voltages with decreased subthreshold swing. To achieve current device requirements, scaling the dimension of TFT is seen as a potential method by many researchers. Scaling also scales the dielectric thickness. Kumar et al. [28] reported that downscaling has improved electrical parameters like $I_{o r} / I_{\text {off }}$, $\mu_{f e}$, SS but at the cost of increasing tunneling gate leakage current. To cop up with this, Vyas et al. [29] suggested that high- $k$ dielectric material like $\mathrm{Al}_{2} \mathrm{O}_{3}, \mathrm{HfO}_{2}$ etc. can improve the electrical performance of TFTs. High- $k$ material is physically thick without being electrically thicker, leading to the same effect of scaling $\mathrm{SiO}_{2}$ without increasing the leakage current. Many TFT applications like active-matrix liquidcrystal display (AMLCD), active-matrix organic lightemitting diode (AMOLED), bio medical devices etc. also require temperature analysis as it tells the working temperature range of the device. Considering all the above aspects, a 2D simulation of a-ITZO TFT along with its RF and analog analysis is thoroughly done by varying different physical parameters. It is seen that a-ITZO material based TFT is a promising option for future RF and analog devices.

The organization of the work is as follows: Section 2 deals with the TFT simulation approach including dimensions, materials and their properties. Section 3 deals with the simulation result, analysis and discussion about impact of different dielectric material, dielectric material thickness $\left(D_{t}\right)$ and temperature $(\mathrm{T})$ on DC, Analog and RF parameters. The application of a-ITZO TFT as resistive load inverter is discussed in Section 4.

\section{TFT Simulation Approach}

Figure 1 shows Bottom Gate Top Contact (BGTC) TFT. Device material parameter used for simulation are tabulated in Table 1 [22, 30-32]. Here, Molybdenum (Mo) is chosen as contact material because of its low work function $(4.3-4.9 \mathrm{eV})$, low contact resistance (5.6-85.5 $\Omega-\mathrm{cm})$, high strength, high melting point and low reactivity to ambient condition like moisture, oxygen etc. [33]. The TCAD simulation have been done using ATLAS simulator on 2D grid. Newton method is employed to do the calculations. For carrier transport, drift diffusion and energy balance models have been considered. Fermi Dirac model are used for carrier distribution. The TFT uses disordered semiconductors which has defect states that can trap the charges. So, the models that define defect density are also included. To accurately model this, a continuous distribution of the sub-gap DOS $(\mathrm{G}(\mathrm{E}))$ given by Eq. 1, is extended from the valence band edge $\left(E_{V}\right)$ to conduction band edge $\left(\mathrm{E}_{\mathrm{c}}\right)$ which include four bands i.e. two tail bands and two deep energy bands and are modeled by Gaussian distribution.

$G(E)=G_{T A}(E)+G_{T D}(E)+G_{G A}(E)+G_{G D}(E)$

It is assumed that for a-ITZO, $G(E)$ consist of three bands i.e. $G_{T A}(E), G_{T D}(E)$ and $G_{G D}(E)$ [34]. These are given by Eqs. 2, 3 and 4 .

$$
\begin{aligned}
& G_{T A}(E)=N_{T A} \exp \left[\frac{E-E_{C}}{W_{T A}}\right] \\
& G_{T D}(E)=N_{T D} \exp \left[\frac{E_{V}-E}{W_{T D}}\right]
\end{aligned}
$$

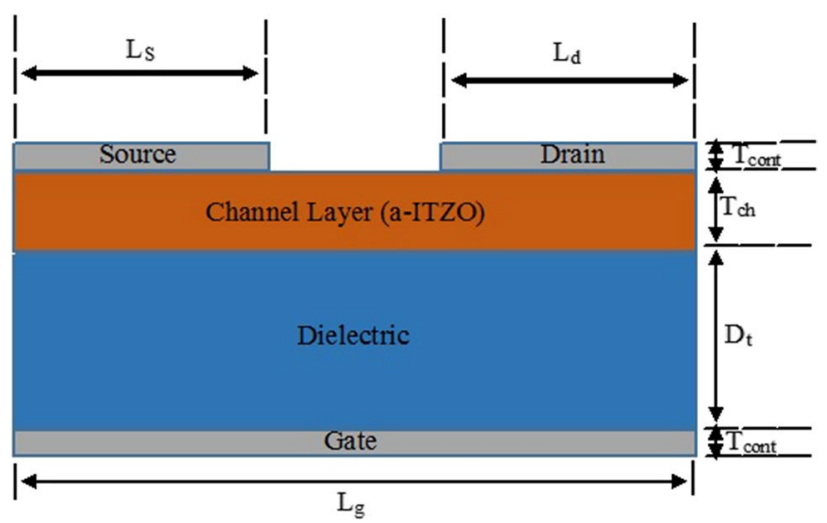

Fig. 1 Structure of the 2D cross sectional a-ITZO TFT 
Table 1 Material and Density of State (DOS) parameter of a-ITZO

\begin{tabular}{|c|c|c|}
\hline \multirow[t]{9}{*}{ a-ITZO Parameters } & Band Gap & $3.02 \mathrm{eV}$ \\
\hline & Dielectric Constant & 10 \\
\hline & Affinity & $4.65 \mathrm{eV}$ \\
\hline & Electron mobility & $0.1 \mathrm{~cm}^{2} \mathrm{~V}^{-1} \mathrm{~s}^{-1}$ \\
\hline & Hole mobility & $30 \mathrm{~cm}^{2} \mathrm{~V}^{-1} \mathrm{~s}^{-1}$ \\
\hline & Effective density of states in the conduction band, $\mathrm{N}_{\mathrm{C}}$ & $1.59 \mathrm{e} 19 \mathrm{~cm}^{-3}$ \\
\hline & Effective density of states in the valance band, $\mathrm{N}_{\mathrm{V}}$ & $1.21 \mathrm{e} 19 \mathrm{~cm}^{-3}$ \\
\hline & Carrier concentration $(\mathrm{N})$ & $4.62 \mathrm{e} 15 \mathrm{~cm}^{-3}$ \\
\hline & Thickness (Tch) & $20 \mathrm{~nm}$ \\
\hline \multirow[t]{9}{*}{ Dielectric Parameters } & Band Gap, $\mathrm{SiO}_{2}$ & $9 \mathrm{eV}$ \\
\hline & Permittivity, $\mathrm{SiO}_{2}$ & 3.9 \\
\hline & Band Gap, $\mathrm{Si}_{3} \mathrm{~N}_{4}$ & $5 \mathrm{eV}$ \\
\hline & Permittivity, $\mathrm{Si}_{3} \mathrm{~N}_{4}$ & 7.5 \\
\hline & Band Gap, $\mathrm{Al}_{2} \mathrm{O}_{3}$ & $8.7 \mathrm{eV}$ \\
\hline & Permittivity, $\mathrm{Al}_{2} \mathrm{O}_{3}$ & 9.5 \\
\hline & Band Gap, $\mathrm{HfO}_{2}$ & $5.7 \mathrm{eV}$ \\
\hline & Permittivity, $\mathrm{HfO}_{2}$ & 35 \\
\hline & Thickness (Dt) & variable $(\mathrm{nm})(150,200,250,300)$ \\
\hline \multirow[t]{7}{*}{ a-ITZO, Density of Defects Parameters } & Peak density of acceptor-like states, $\mathrm{N}_{\mathrm{TA}}$ & $1.22 \mathrm{e} 18 \mathrm{~cm}^{-3} \mathrm{eV}^{-1}$ \\
\hline & Peak density of donor-like states, $\mathrm{N}_{\mathrm{TD}}$ & $1.30 \mathrm{e} 20 \mathrm{~cm}^{-3} \mathrm{eV}^{-1}$ \\
\hline & Characteristic decay energy (acceptor-like states), $\mathrm{W}_{\mathrm{TA}}$ & $0.016 \mathrm{eV}$ \\
\hline & Characteristic decay energy (donor-like states), $\mathrm{W}_{\mathrm{TD}}$ & $0.20 \mathrm{eV}$ \\
\hline & Peak density (shallow donor Gaussian), $\mathrm{N}_{\mathrm{GD}}$ & $1.73 \mathrm{e} 16 \mathrm{~cm}^{-3} \mathrm{eV}^{-1}$ \\
\hline & Decay energy (shallow donor Gaussian), $\mathrm{W}_{\mathrm{GD}}$ & $0.082 \mathrm{eV}$ \\
\hline & Energy peak (shallow donor Gaussian) $\mathrm{E}_{\mathrm{GD}}$ & $2.9 \mathrm{eV}$ \\
\hline \multirow[t]{3}{*}{ Source/ Drain/ Gate Parameters } & Gate (Molybdenum) Length (Lg)/Width (W) /Tcont & $35 \mu \mathrm{m} / 10 \mu \mathrm{m} / 0.1 \mathrm{~nm}$ \\
\hline & Molybdenum Source and Drain (Ls \& Ld/W/Tcont) & $15 \mu \mathrm{m} / 10 \mu \mathrm{m} / 0.1 \mathrm{~nm}$ \\
\hline & Work Function of Molybdenum ( $\Phi$ s) & $4.53 \mathrm{eV}$ \\
\hline
\end{tabular}

$G_{G D}(E)=N_{G D} \exp \left[-\left[\frac{E-E_{G D}}{W_{G D}}\right]^{2}\right]$

Where, E is the trap energy and the subscript T, A, G and D stands for tail, acceptor, Gaussian (Deep level) and donor states. To verify the simulation results, the simulation parameters are calibrated with the results available for TFT [34] and obtained in Fig. 2. It can be deduced that TCAD simulation results are in excellent agreement with the results obtained by taouririt et al. [34]. Further, Analog/ RF analysis of a-ITZO TFT by introducing different physical variations have been discussed.

\section{RF/ Analog Analysis of a-ITZO TFT}

This section deals with the calculation and analysis of Analog/ RF performance parameters for a-ITZO TFT using the expressions mentioned in Table 2. The primary Figure of Merits (FOM's) i.e. drain current $\left(I_{D S}\right), g_{d}, R_{O}, g_{m}$, TGF, $V_{E A}, A_{V}$, gate to source $\left(C_{G S}\right)$ and gate to drain $\left(C_{G D}\right)$ capacitances, $f_{T}, F_{\text {max }}$,

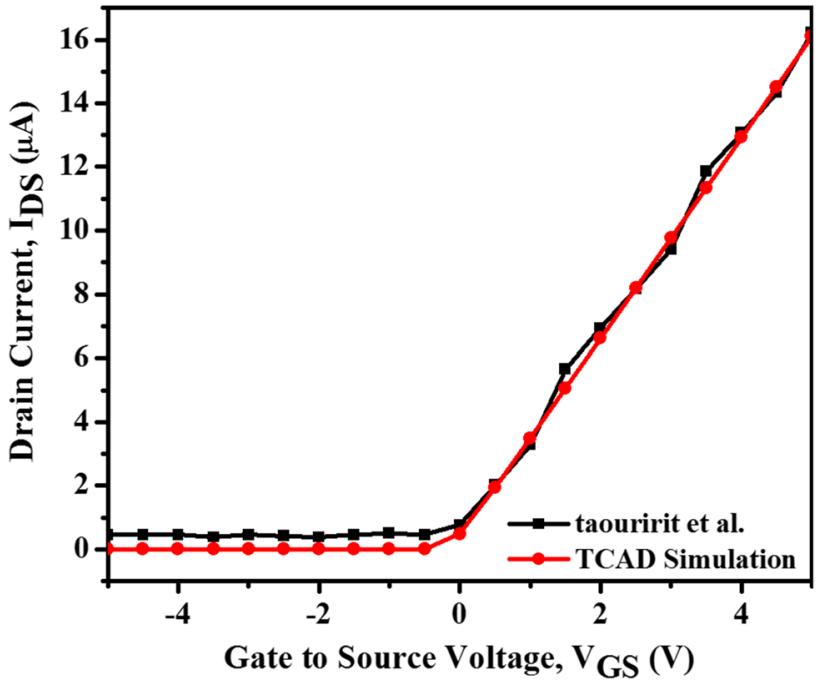

Fig. 2 Comparison of the transfer characteristics of TFT results reported in [34] and a-ITZO TFT (TCAD simulation) for Drain-toSource Voltage $\mathrm{V}_{\mathrm{DS}}=5 \mathrm{~V}$ 
TFP, GFP, GBP and GTFP and the impact of physical parameter i.e. dielectric material, dielectric thickness $\left(D_{t}\right)$ and temperature (T) of a-ITZO TFT on Analog/RF performance is analyzed in the below subsections.

\subsection{Impact of High K Dielectric Material on the DC, Analog and RF Parameters}

In last few decades, $\mathrm{SiO}_{2}$ was mainly used as dielectric material and have shown good electrical performance. As the technology is changing, there is a need of miniaturized devices to fulfill the requirement of future thin film electronic market. As the device dimensions are scaling down, dielectric layer thickness is also scaling, which has a positive impact on device performance. The dielectric thickness $\left(D_{t}\right)$ scaling also increases (Eq. 5) capacitance per unit area $\left(C_{o x}\right)$ that directly increases the drain current of the device [23].

$C_{o x}=\frac{\varepsilon_{\mathrm{o}} \cdot \mathrm{k}_{\mathrm{ox}} \cdot \mathrm{L} \cdot \mathrm{W}}{\mathrm{T}_{\mathrm{ox}}}$

Where $\mathrm{L}, \mathrm{W}, \mathrm{T}_{\mathrm{ox}}$ are the length, width and thickness of dielectric, $\mathrm{k}_{\mathrm{ox}}$ is the dielectric constant and $\varepsilon_{\mathrm{o}}$ is the absolute permittivity. To solve the thickness scaling problem, high- $k$ dielectric material instead of low- $k$ dielectric have been used. High-k dielectric material is recognized by Effective Oxide Thickness (EOT) which means that it is electrically thick without being physically thick which results in increased capacitances and reduced leakage current [34]. In this section, the impact of high- $k$ material $\left(\mathrm{SiO}_{2}, \mathrm{Si}_{3} \mathrm{~N}_{4}\right.$, $\mathrm{Al}_{2} \mathrm{O}_{3}$ and $\mathrm{HfO}_{2}$ ) on DC, analog and RF performance of
a-ITZO TFT have been studied where dielectric thickness $\left(D_{t}\right)$ was considered as $200 \mathrm{~nm}$ during the simulation.

The plot of different analog/RF parameters with variation in dielectric material is shown in Fig. 3. Figure 3(a-d) shows the variation of $I_{D S}, g d, R_{O}, V_{E A}, A_{V}$, gm and TGF for different high- $k$ materials. Drain current $\left(\mathrm{I}_{\mathrm{DS}}\right)$ in linear and $\log$ scale w.r.t. $\mathrm{V}_{\mathrm{GS}}$ is shown in Fig. 3(a). The peak value of increases from $95 \mu \mathrm{A}$ to $825 \mu \mathrm{A}$ when the dielectric material changed from $\mathrm{SiO}_{2}$ to $\mathrm{HfO}_{2}$. The electrical parameters are extracted from this curve and tabulated in Table 3. It is seen from Table 3 that and $I_{o n}$ / are mostly affected with this change. Also, there is an increased shift in threshold voltage $\left(V_{t h}\right)$ because of the reduction of surface material potential along the channel [37]. Figure 3(b) demonstrates the output characteristics and drain conduction () for a-ITZO TFT for different dielectric material at $V_{G S}=5 \mathrm{~V}$.

The right axis (Fig. 3(b)) depicts the output characteristics and it is seen that when $V_{D S}>5 \mathrm{~V}$, the drain current starts to saturate for all the dielectric materials, however it has higher value for $\mathrm{HfO}_{2}$ based TFT. The reason for this change is increased capacitance per unit area because of decreased effective thickness (Eq. 5). The Drain conductance $\left(g_{d}\right)$ is derived from output characteristics and is plotted on left axis of Fig. 3(b). The same rise is seen in $g_{d}$ as that of $I_{D S}$ for $\mathrm{HfO}_{2}$ based TFT. The inverse of $g_{d}$ is known as output resistance $\left(R_{O}\right)$. The inset of Fig. 3(c) shows the variation of $R_{O}$ with $V_{D S}$ for various dielectric materials. It is found that TFT with $\mathrm{HfO}_{2}$ dielectric has low $R_{O}$ of $2.95 \mathrm{M} \Omega$ as compared to $\mathrm{SiO}_{2}$ based TFT having $R_{O}$ of $16.86 \mathrm{M} \Omega$. As a result of this, $\mathrm{HfO}_{2}$ based TFT shows superior $I_{D S}$ values than $\mathrm{SiO}_{2}$ based dielectric TFT (Fig. 3(a)).
Table 2 Symbols and expressions $[35,36]$

\begin{tabular}{|c|c|c|c|}
\hline Symbol & Quantity & Unit & Expression \\
\hline $\mathrm{g}_{\mathrm{d}}$ & Drain Conductance & $\mathrm{S}$ & $g_{d}=\frac{d I_{D S}}{d V_{D S}} \mid V_{G S}=$ Const. \\
\hline $\mathrm{R}_{\mathrm{O}}$ & Output Resistance & $\Omega$ & $R_{O=} \frac{1}{g_{d}}$ \\
\hline$V_{E A}$ & Early Voltage & $\mathrm{V}$ & $V_{E A}=\frac{I_{D S}}{g_{d}}$ \\
\hline$A_{V}$ & Intrinsic Gain & $\mathrm{dB}$ & $A_{V}=\frac{g_{m}}{g_{V}}$ \\
\hline$g_{m}$ & Transconductance & $S$ & $g_{m}=\frac{d_{d}^{g_{D S}}}{d V_{G S}}||_{D S}=$ Const. \\
\hline TGF & Transconductance Generation Factor & $\mathrm{V}^{-1}$ & $\mathrm{TGF}=\frac{I_{D S}}{=g_{m}}$ \\
\hline$f_{T}$ & Cut-off Frequency & $\mathrm{Hz}$ & $f_{T}=\frac{g_{m}}{2 \prod\left(C_{G S}+C_{G D}\right)}$ \\
\hline GBP & Gain Bandwidth Product & $\mathrm{Hz}$ & $\mathrm{GBP}=\frac{g_{m}}{20 \prod C_{G D}}$ \\
\hline$F_{\max }$ & Maximum frequency of operation & $\mathrm{Hz}$ & $\begin{array}{c}F_{\max }=\sqrt{\frac{f_{T}}{8 \prod R_{G} C_{G D}}}, \\
\text { Where, }\left(R_{G}=\frac{1}{G_{g g}}\right)\end{array}$ \\
\hline TFP & Transconductance Frequency Product & $\mathrm{Hz}$ & $\mathrm{TFP}=\left(\frac{g_{m}}{I_{D S}}\right)^{*} f_{T}$ \\
\hline GFP & Gain Frequency Product & $\mathrm{Hz}$ & $\mathrm{GFP}=\left(\frac{g_{m}}{g_{d}}\right) * f_{T}$ \\
\hline GTFP & Gain Transconductance Frequency Product & $\mathrm{Hz}$ & $\mathrm{GTFP}=\left(\frac{g_{m}}{g_{d}}\right) * \mathrm{TFP}$ \\
\hline
\end{tabular}




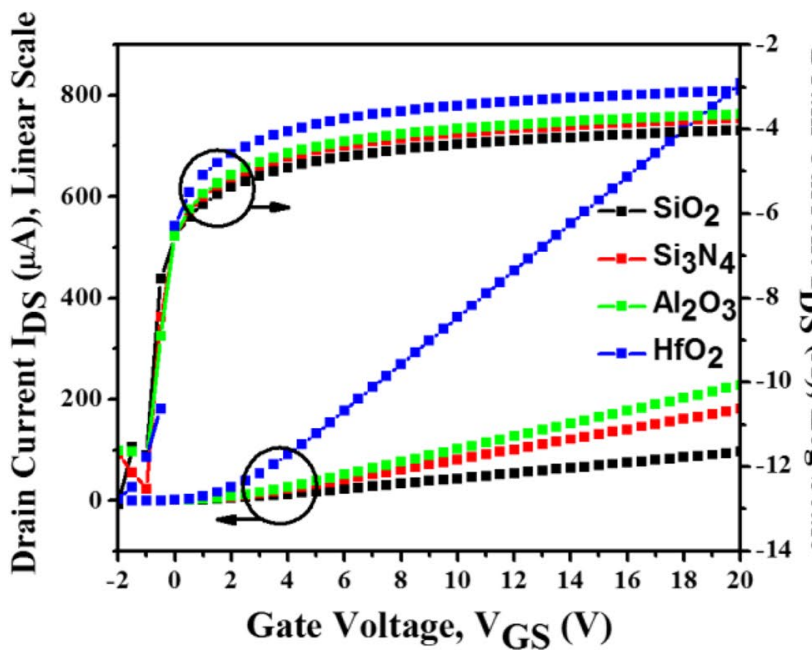

(a)

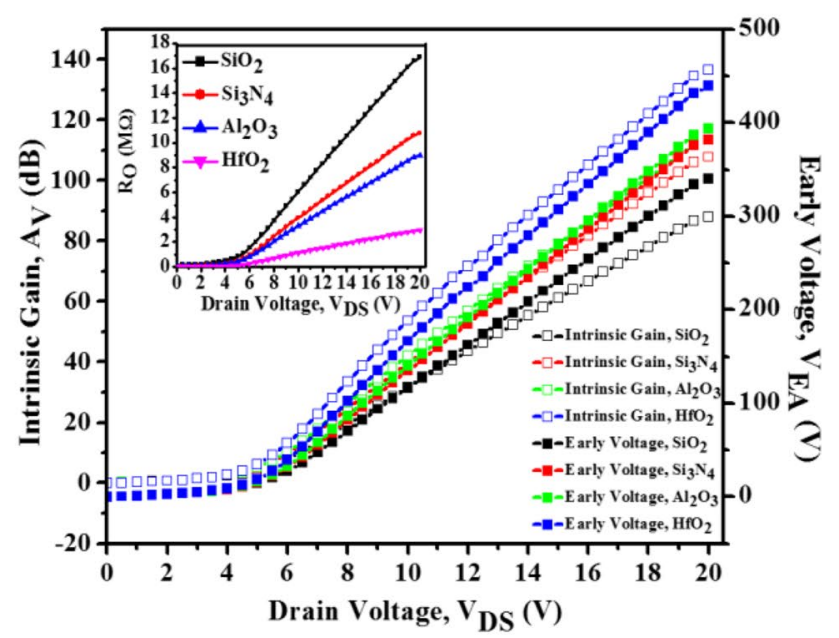

(c)

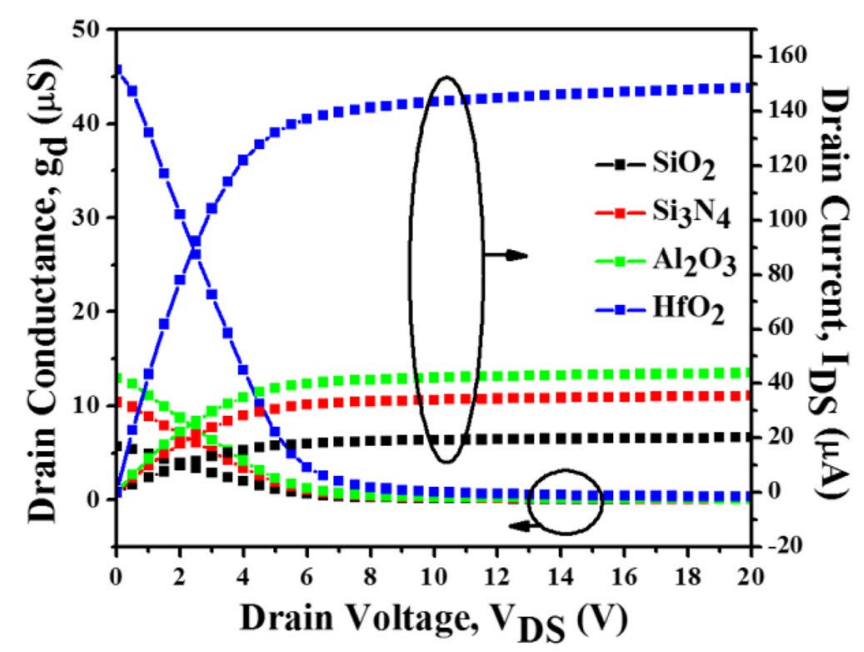

(b)

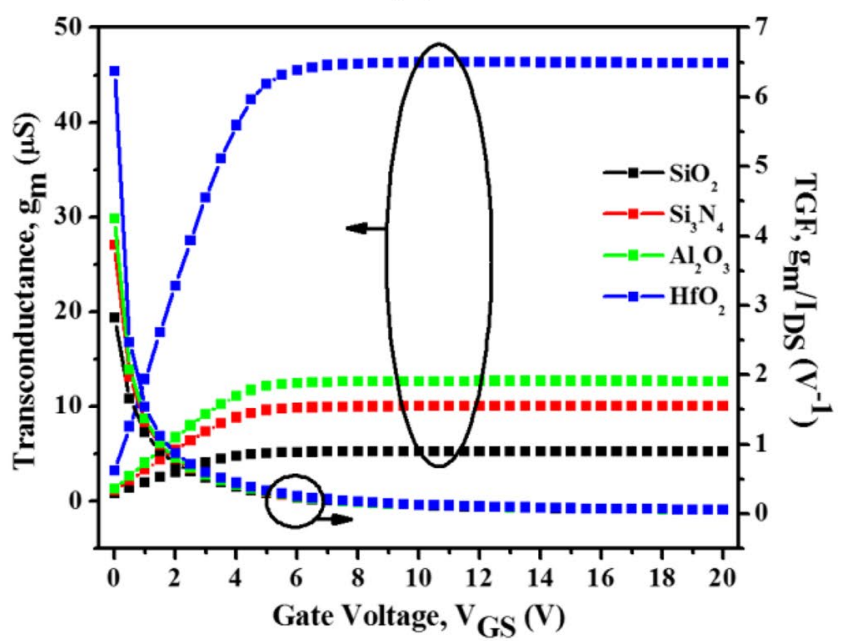

(d)

Fig. 3 a $I_{D S}$ (Linear and Log) (b) $g_{d} \&$ Output $I_{D S}$ (c) $R_{O}$ (Inset), $V_{E A}$ and $A_{V}$ (d) $g_{m} \&$ TGF for different dielectric materials

Table 3 Extracted parameters: $V_{t}, V_{o n}, \mathrm{SS}, I_{o n}, I_{o f f}$ depending on dielectric material variation

\begin{tabular}{llllllr}
\hline Dielectric & $\begin{array}{l}V_{t} \\
(\mathrm{~V})\end{array}$ & $V_{\text {on }}(\mathrm{V})$ & $\begin{array}{l}\text { Sub-Threshold } \\
\text { Swing (V/decade) }\end{array}$ & \multicolumn{1}{l}{$\begin{array}{l}I_{\text {on }} \\
(\mathrm{A})\end{array}$} & \multicolumn{1}{l}{$\begin{array}{l}I_{\text {off }} \\
(\mathrm{A})\end{array}$} & $I_{\text {on }} / I_{\text {off }}$ \\
\hline $\mathrm{SiO}_{2}$ & 1.75 & -0.70 & 1.0775 & $9.387 \cdot 10^{-5}$ & $2.36 \cdot 10^{-12}$ & $3.97 \cdot 10^{7}$ \\
$\mathrm{Si}_{3} \mathrm{~N}_{4}$ & 1.97 & -0.50 & 0.8492 & $1.790 \cdot 10^{-4}$ & $1.75 \cdot 10^{-12}$ & $1.01 \cdot 10^{8}$ \\
$\mathrm{Al}_{2} \mathrm{O}_{3}$ & 2.03 & -0.46 & 0.7945 & $2.262 \cdot 10^{-4}$ & $4.07 \cdot 10^{-13}$ & $5.55 \cdot 10^{8}$ \\
$\mathrm{HfO}_{2}$ & 2.19 & -0.29 & 0.6216 & $8.232 \cdot 10^{-4}$ & $4.11 \cdot 10^{-13}$ & $1.99 \cdot 10^{9}$ \\
\hline
\end{tabular}

The analog performance is further analyzed by the graph of early voltage $\left(V_{E A}\right)$ and intrinsic gain $\left(A_{V}\right)$ plotted in Fig. 3(c). The variation in $V_{E A}$ is $29 \%$ when dielectric material is changed from $\mathrm{SiO}_{2}$ to $\mathrm{HfO}_{2}$ for a-ITZO TFT. This higher value of $V_{E A}$ has a good sign as it tells that the simulated TFT has better control on channel length modulation and DIBL. The left axis of Fig. 3(c) shows the variation of intrinsic gain $\left(A_{V}\right)$ with $V_{D S}$. It is defined as the ratio of transconductance $\left(g_{m}\right)$ by drain conductance $\left(g_{d}\right)$. An increase of nearly $55 \%$ in $A_{V}$ is observed for $\mathrm{HfO}_{2}$ based a-ITZO TFT as compared to $\mathrm{SiO}_{2}$ material based TFT. The reason for this improvement is that $\mathrm{HfO}_{2}$ will provide high capacitance per unit area with large physical thickness and also provide better immunity to SCE's, that will increase the current and hence it will improve the transistor analog performance parameters $g_{m}, A_{V}$. 
A combined plot of TGF and $g_{m}$ is drawn as a function of $V_{G S}$ in Fig. 3(d). The left axis of the figure shows that greater value of transconductance $\left(\sim 10^{-5} \mathrm{~S}\right)$ is attained for a-ITZO TFT with $\mathrm{HfO}_{2}$ as dielectric. The increment in $g_{m}$ with high- $k$ material is because of increase in drain to source current of device. Effective use of current to achieve desired value of transconductance is determined by TGF. TGF is a major performance parameter for analog applications which indicates TFT's capability to amplify a signal for a certain $I_{D S}$. The value of TGF also increases with high- $k$ dielectric material. This trend follows as that of maximum $g_{m} / I_{D S}$ is for a-ITZO TFT with $\mathrm{HfO}_{2}$ dielectric followed by $\mathrm{Al}_{2} \mathrm{O}_{3}, \mathrm{Si}_{3} \mathrm{~N}_{4}$ and $\mathrm{SiO}_{2}$ for $V_{G S}<2 \mathrm{~V}$. It is also observed that with increasing $V_{G S}$, TGF value starts to decrease for all configurations.
This analysis is very beneficial for circuit designers working on analog applications.

Figure 4(a-d) represent the calculation of RF parameters i.e. $C_{G S}$ and $C_{G D}$, GBP, $f_{T}, F_{\max }$, GTFP, TFP and GFP with respect to different dielectric materials. The RF analysis for the a-ITZO TFT is done from AC analysis by including frequency of $1 \mathrm{MHz}$ after post processing of DC solution. The $C_{G S}$ and $C_{G D}$ values for different dielectric material TFT is plotted in Fig. 4(a). It is seen that capacitance values have incremental nature with high $k$ material because of the increased fringing field density in the device [36]. The value of $C_{G S}$ and $C_{G D}$ are almost same for $\mathrm{SiO}_{2}, \mathrm{Si}_{3} \mathrm{~N}_{4}$ and $\mathrm{Al}_{2} \mathrm{O}_{3}$. The variation in $C_{G S}$ and $C_{G D}$ values for a-ITZO TFT for $\mathrm{HfO}_{2}$ dielectric is from $253 \mathrm{fF}$ (at $V_{G S}=0 \mathrm{~V}$ ) to $274 \mathrm{fF}$ (at

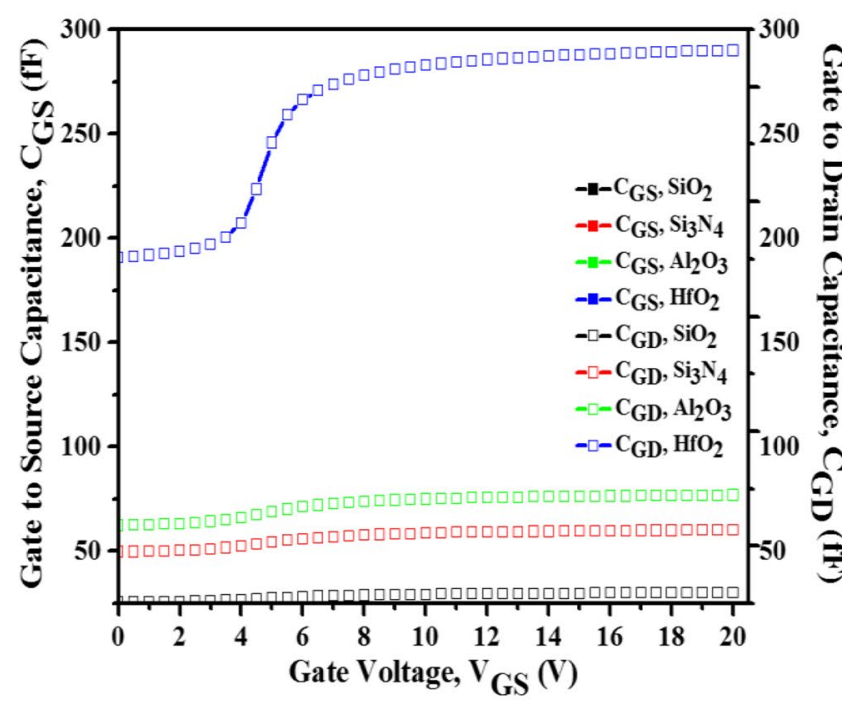

(a)

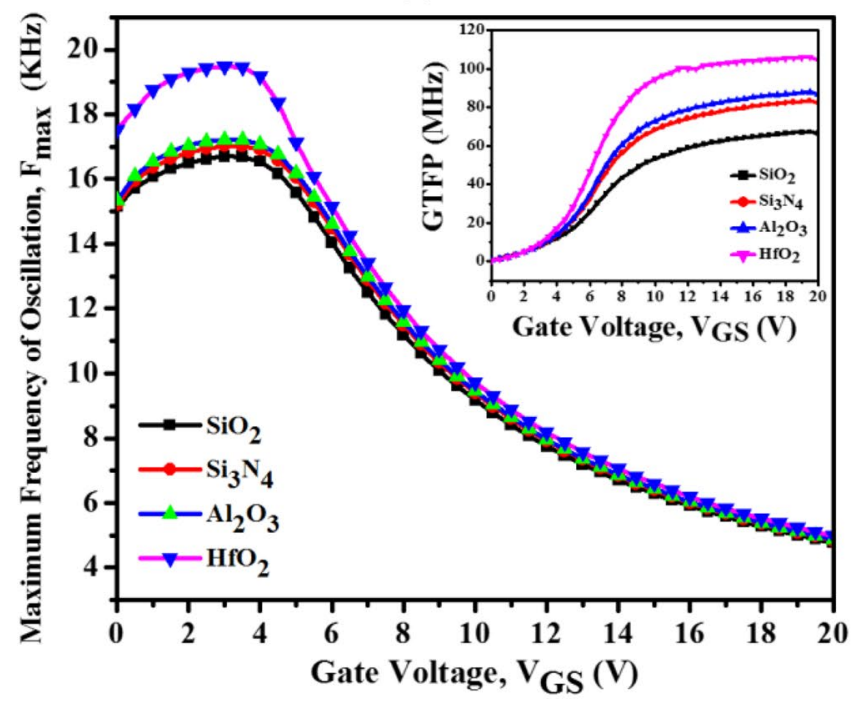

(c)

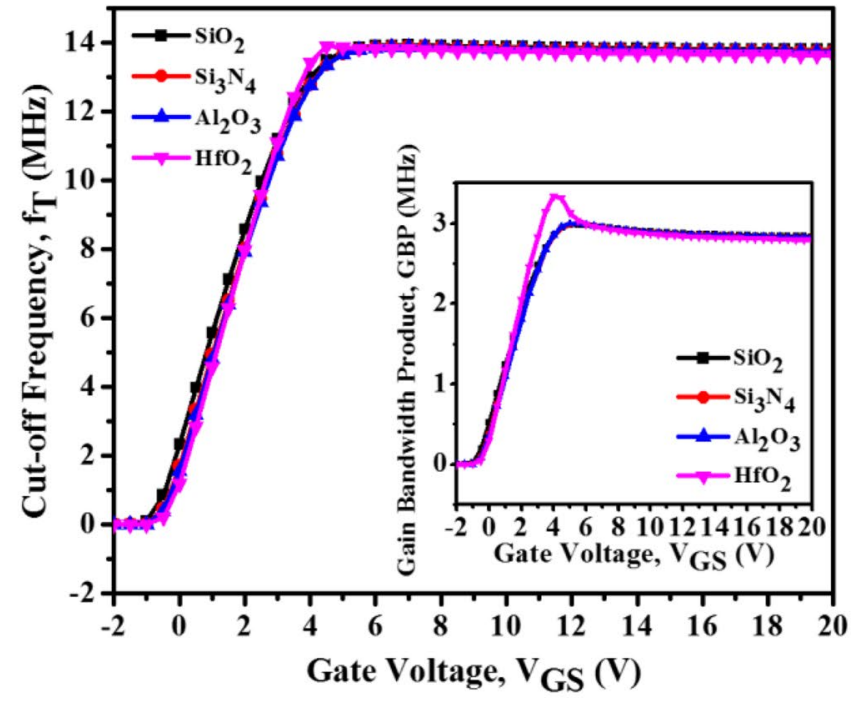

(b)

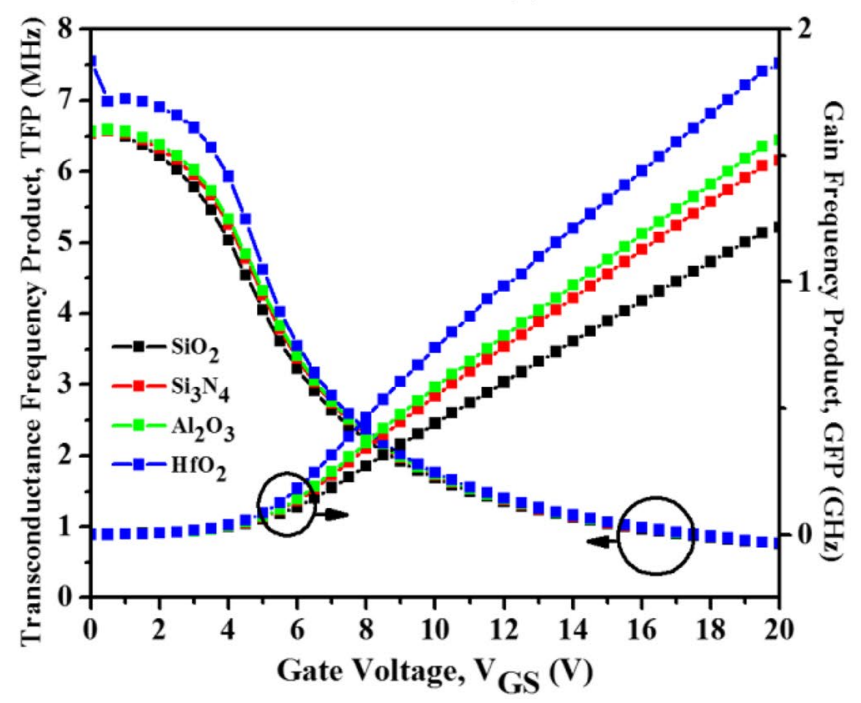

(d)

Fig. 4 a $C_{G S} \& C_{G D}$ (b) $f_{T} \&$ GBP (Inset) (c) $F_{\max } \&$ GTFP (inset) (d) TFP \& GFP for different dielectric materials 
$V_{G S}=20 \mathrm{~V}$ ) and $176 \mathrm{fF}$ (at $V_{G S}=0 \mathrm{~V}$ ) to $266 \mathrm{fF}$ (at $V_{G S}=$ $20 \mathrm{~V})$ respectively.

Unity gain cut-off Frequency $\left(f_{T}\right)$ is another FOM for high-speed digital application. The variation of $f_{T}$ against $V_{G S}$ in plotted in Fig. 4(b). It is a potential characteristic for devices in defining the acceptable bandwidth range so that they can be used for RF application. As depicted from the Fig. 4(b), there is a slight variation in $f_{T}$ with changing dielectric material from low to high- $k$. This trend is seen because the rate of improvement in $g_{m}$ is higher than that of capacitances. Inset of Fig. 4(b) shows the variation of GBP with $V_{G S}$. Close analysis of the curve shows both $\left(f_{T} \&\right.$ GBP $)$ have same nature with $V_{G S}$. At $V_{G S}=4 \mathrm{~V}$, the peak value of $f_{T}$ and GBP for a-ITZO TFT with $\mathrm{HfO}_{2}$ dielectric is 13.42 Mhz and 3.34 MHz respectively.

The plot of maximum frequency of oscillation $\left(F_{\max }\right)$ with $V_{G S}$ is shown in Fig. 4(c). $F_{\text {max }}$ determines the transit frequency at which maximum power gain is available. $F_{\max }$ value shows decreasing trend with $V_{G S}$. The a-ITZO TFT with $\mathrm{HfO}_{2}$ dielectric achieve nearly 0.17 times increase in $F_{\text {max }}$ than a-ITZO TFT with $\mathrm{SiO}_{2}$ dielectric. GTFP allows the circuit designers to identify the best region of operation by trading off gain, transconductance and speed. As seen from the inset of Fig. 4(c), GTFP value increases by nearly $55 \%$ when using $\mathrm{HfO}_{2}$ as dielectric with a-ITZO TFT than by using $\mathrm{SiO}_{2}$ because of higher value of $f_{T}$ and $g_{m}$ for the former.

Figure 4(d) represent the variation of TFP and GFP w.r.t $V_{G S}$ for different dielectric materials. TFP defines the tradeoff between power and bandwidth. As seen from the curve that high TFP value is achieved for a-ITZO TFT with high$k$ dielectric at $V_{G S}<4 \mathrm{~V}$ and after that it is decreased as $V_{G S}$ is increased. GFP as seen from right axis of Fig. 4(d) shows linear rise with the $V_{G S}$. The GFP for a-ITZO TFT with $\mathrm{HfO}_{2}$ dielectric has 0.5 times more GFP value than its $\mathrm{SiO}_{2}$ counterpart.

\subsection{Impact of Dielectric Thickness $\left(D_{t}\right)$ on the $D C$, Analog and RF Parameters}

As deduced from the last analysis, DC, analog/RF parameters are affected by dielectric material. Changing the low- $k$ material to high- $k$ implies low power, low leakage and highperformance electronic devices. In this section, impact of $D_{t}$ scaling is seen on different Analog/RF parameters. Thickness of the dielectric material is inversely proportional to capacitance. As the thickness of dielectric material reduces, it increases the capacitance which in turn induces more number of charge carriers at the same output voltage and increases the drain current. $g_{m}$ will also improve by variation of gate capacitance, which results in reduction of extrinsic delays in digital circuits. Figures 5 and 6 shows the calculation of different Analog/RF parameters of a-ITZO TFT with $\mathrm{HfO}_{2}$ as dielectric material. The device is simulated and compared for different dielectric thickness $\left(D_{t}\right)=150$ $\mathrm{nm}, 250 \mathrm{~nm}, 300 \mathrm{~nm}$ and $350 \mathrm{~nm}$.

Figure 5(a) represent the calculation of $I_{D S}$ in linear and $\log$ scale w.r.t $V_{G S}$ at $V_{D S}=5 \mathrm{~V}$. The peak value of $I_{D S}$ is 1.1 $\mathrm{mA}, 824 \mu \mathrm{A}, 661 \mu \mathrm{A}, 552 \mu \mathrm{A}$ for $D_{t}$ of $150 \mathrm{~nm}, 200 \mathrm{~nm}, 250$ $\mathrm{nm}$ and $300 \mathrm{~nm}$ respectively. The increment in $I_{D S}$ is due to the increase of capacitive coupling between gate and channel with low dielectric thickness. The different parameters like $V_{t}, V_{o n}, \mathrm{SS}, I_{o n}, I_{\text {off }}$ were extracted from the linear and log transfer curves and tabulated in Table 4 . The $I_{\text {off }}$ state current for all the dielectric thickness is found in the range of $10^{-13}$ to $10^{-14}$. This value is above the requirement of ITRS for low power application.

The right axis of Fig. 5(b) shows output current $\left(I_{D S}\right)$ w.r.t $V_{D S}$ at constant $V_{G S}=5 \mathrm{~V}$ for different dielectric thickness $\left(D_{t}\right)$. It is evident from the curve that decrease in thickness improves the electrical characteristic and also the performance of the device because of increased dielectric capacitance per unit area $\left[C_{i}\right]$. It is also due to the decrease in the energy band gap of dielectric material [38]. Here, it is seen that all a-ITZO TFT shows excellent saturated characteristic at approx. $V_{D S}=6 \mathrm{~V}$ and the thinnest TFT exhibit highest saturation current. The $g_{d}$ for different dielectric thickness is seen from the left axis of the Fig. 5(b). The $g_{d}$ for $D_{t}=150$ $\mathrm{nm}$ is nearly two times as that of $D_{t}=300 \mathrm{~nm}$. The increase in $g_{d}$ is relied to the minimization of short channel effects (SCE's). Inset of Fig. 5(c) shows the variation of output resistance $\left(R_{O}\right)$ with $V_{D S}$ for different dielectric thickness. The value of $R_{O}$ is approximately same $(\sim 2.90 \mathrm{M} \Omega)$ for all variation of dielectric thickness.

Early voltage $\left(V_{E A}\right)$ and Intrinsic Gain $\left(A_{V}\right)$ are another FOM and their calculation with $V_{D S}$ is represented in the Fig. 5(c). $\mathrm{E}_{\mathrm{VA}}$ is higher for thinnest TFT i.e. nearly $80 \%$ higher than that of $D_{t}=300 \mathrm{~nm}$. The value of $A_{V}$ is $89.3 \mathrm{~dB}$, 109.2 dB, $137.1 \mathrm{~dB}$ and $176.2 \mathrm{~dB}$ for dielectric thickness of $300 \mathrm{~nm}, 250 \mathrm{~nm}, 200 \mathrm{~nm}$ and $150 \mathrm{~nm}$ respectively. Both $\mathrm{E}_{\mathrm{VA}}$ and $A_{V}$ has higher values for thinner TFT and found its use in fast memory and RF amplification application. $g_{m}$ as seen from the left axis of Fig. 5(d) shows inverse trend with dielectric thickness. Higher value of $g_{m}$ is desired to design high performance circuits. It is seen that apex value of $g_{m}$ increases approximately 2 times when $D_{t}$ reduced from $300 \mathrm{~nm}$ to $150 \mathrm{~nm}$. Right axis of Fig. 5(d) revels that considerable improvement in TGF is seen for a-ITZO TFT with a decrease in dielectric thickness. The lower value of subthreshold swing $(0.22 \mathrm{~V} /$ decade $)$ exhibit higher value of $\operatorname{TGF}\left(6.89 \mathrm{~V}^{-1}\right)$ for $D_{t}=150 \mathrm{~nm}$.

Figure 6(a-d) represent the calculation of $C_{G S}, C_{G D}, f_{T}$, GBP, $F_{\max }$, GTFP, TFP and GFP with respect to dielectric thickness $\left(D_{t}\right)$. Figure 6(a) shows the variation of small signal capacitance $C_{G S} \& C_{G D}$ w.r.t $V_{G S}$. The variation in $C_{G S} \& C_{G D}$ values for a-ITZO TFT with dielectric thickness 


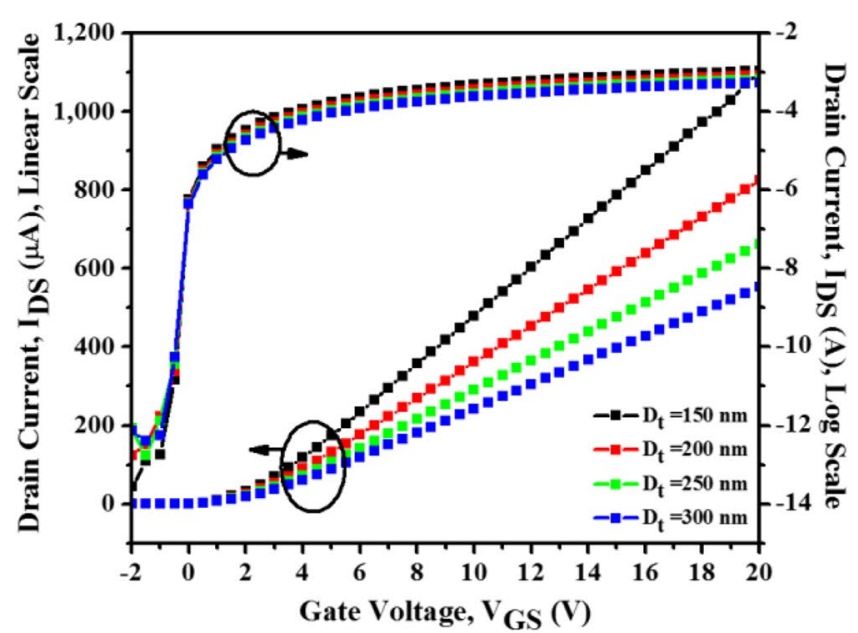

(a)

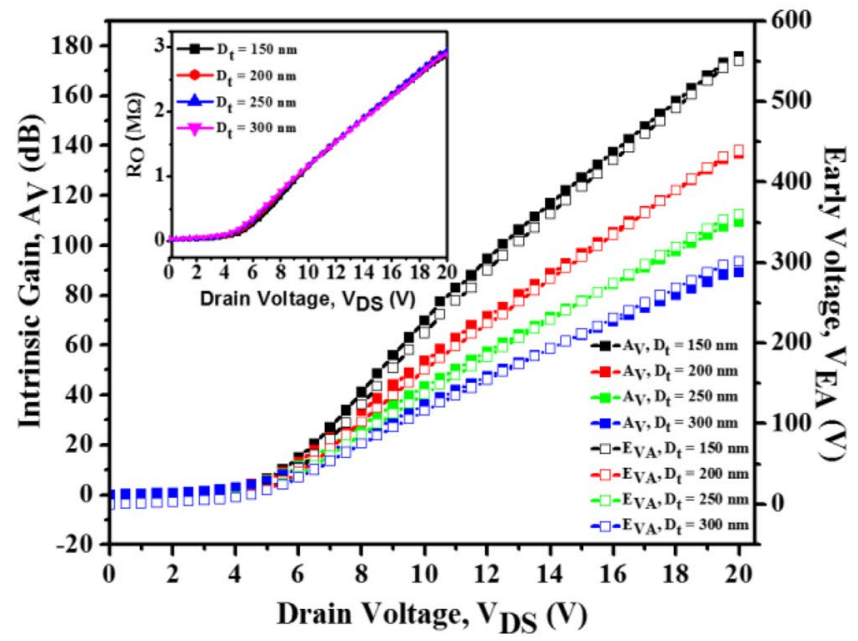

(c)

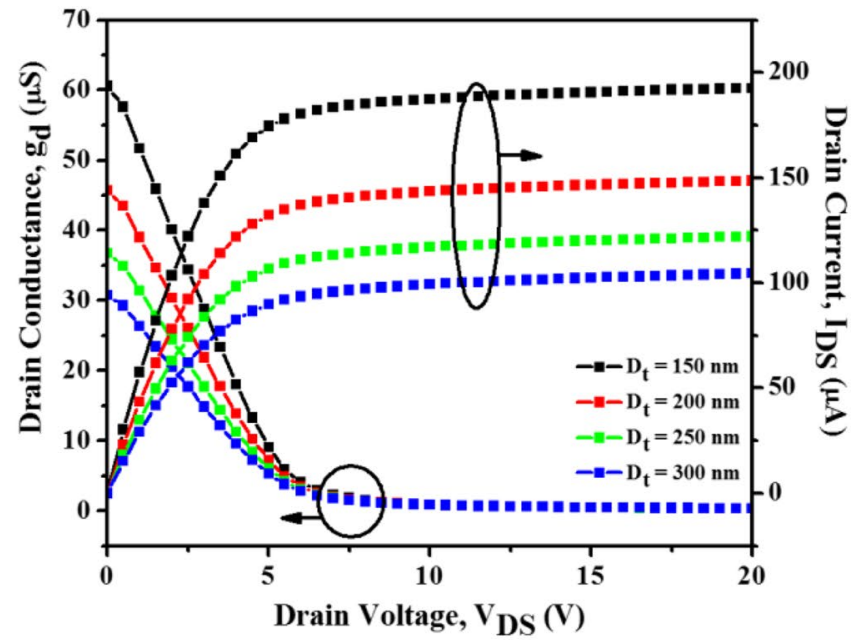

(b)

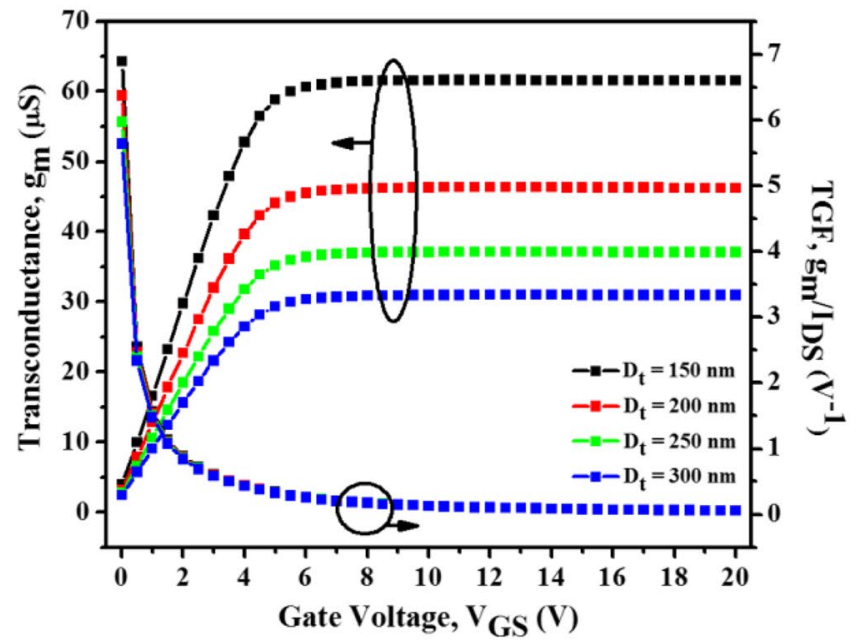

(d)

Fig. 5 a $I_{D S}$ (Linear and Log) (b) $g_{d} \&$ Output $I_{D S}$ (c) $R_{O}$ (Inset), $V_{E A}$ and $A_{V}(\mathbf{d}) g_{m} \&$ TGF for different values of $D_{t}$

$D_{t}=150 \mathrm{~nm}$ is from $220 \mathrm{fF}\left(V_{G S}=0 \mathrm{~V}\right)$ to $365 \mathrm{fF}\left(V_{G S}=\right.$ $20 \mathrm{~V}$ ) and $214 \mathrm{fF}$ (at $V_{G S}=0 \mathrm{~V}$ ) to $354 \mathrm{fF}$ (at $V_{G S}=20 \mathrm{~V}$ ) respectively. From circuit designer point of view these low values of capacitance are required. These intrinsic capacitances $\left(C_{G S}, C_{G D}\right)$ are used to find cut-off frequency $\left(f_{T}\right)$ which is shown in Fig. 6(b). From figure it is seen that a-ITZO TFT with dielectric thickness $\left(D_{t}=150 \mathrm{~nm}\right)$ yield a peak value of $14.3 \mathrm{Mhz}$ at $V_{G S}=4.5 \mathrm{~V}$. GBP with $V_{G S}$ is shown in the inset of Fig. 6(b). The nature of GBP and $f_{T}$ is similar when $C_{G S}=C_{G D}$ is approximated. a-ITZO TFT using thinner dielectric attains higher GBP. Although the variation is not so much.

The frequency at which power gain is unity is known as maximum frequency of oscillation $\left(F_{\max }\right)$. As evident from the Fig. 6(c), the value of $F_{\max }$ decreases as we increase the $V_{G S}$. The maximum value of $F_{\max }$ at $V_{G S}=3.5 \mathrm{~V}$ for dielectric thickness $\left(D_{t}\right)$ value of $150 \mathrm{~nm}, 200 \mathrm{~nm}, 250 \mathrm{~nm}$ and $300 \mathrm{~nm}$ is $20.4 \mathrm{kHz}, 19.5 \mathrm{kHz}, 18.9 \mathrm{kHz}$ and $18.4 \mathrm{kHz}$ respectively. GTFP is defined as the product of intrinsic gain and TFP as shown in the inset of Fig. 6(c). The highest value of GTFP as obtained for $D_{t}=150 \mathrm{~nm}$ is nearly two times that of GTFP at $D_{t}=300 \mathrm{~nm}$. Figure 6(d) shows the calculation of TFP and GFP w.r.t $V_{G S}$ for different values of $D_{t}$. As seen from the left axis of Fig. 6(d) that there is a slight variation in TFP with change in dielectric thickness. The value of GFP as seen from the right axis of Fig. 6(d) are $1.22 \mathrm{GHz}$, $1.49 \mathrm{GHz}, 1.86 \mathrm{GHz}$ and $2.39 \mathrm{GHz}$ for decreasing dielectric thickness from $300 \mathrm{~nm}$ to $150 \mathrm{~nm}$ in steps of $50 \mathrm{~nm}$ respectively. The betterment of all the above RF parameters with $D t$ is credited to the improved gate control on charge carriers i.e. enhanced electrostatic integrity with decreasing $D t$. 


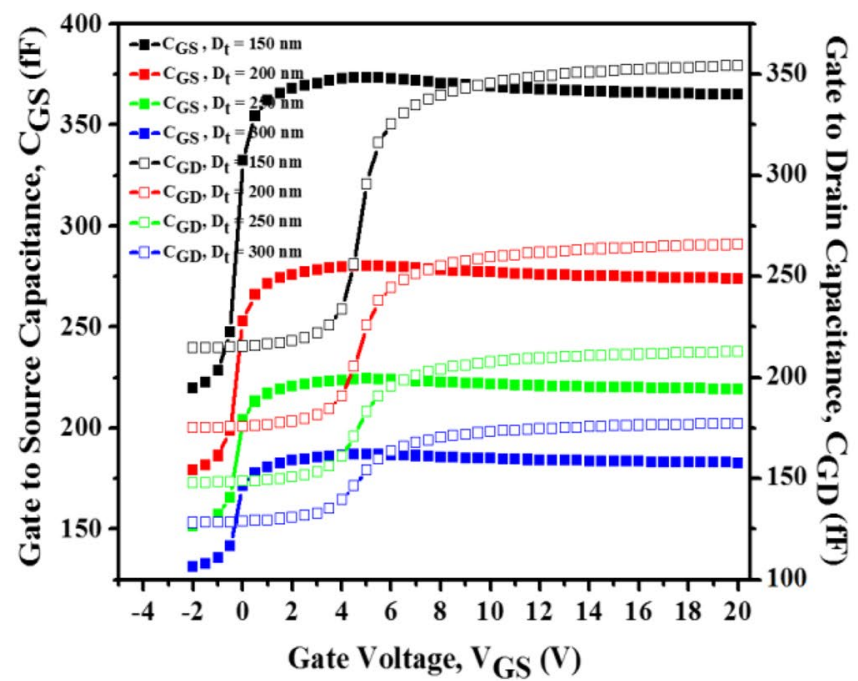

(a)

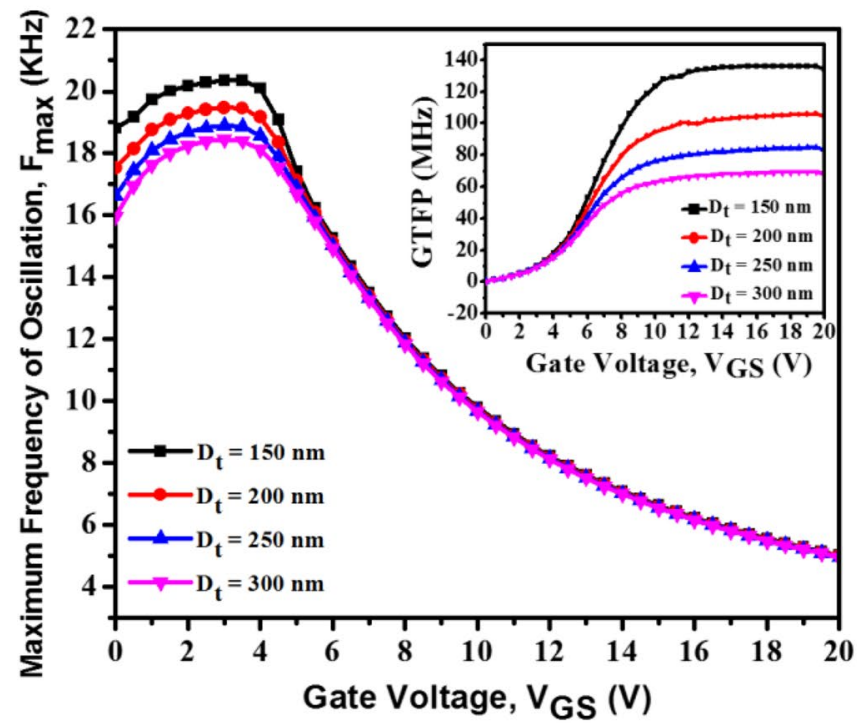

(c)

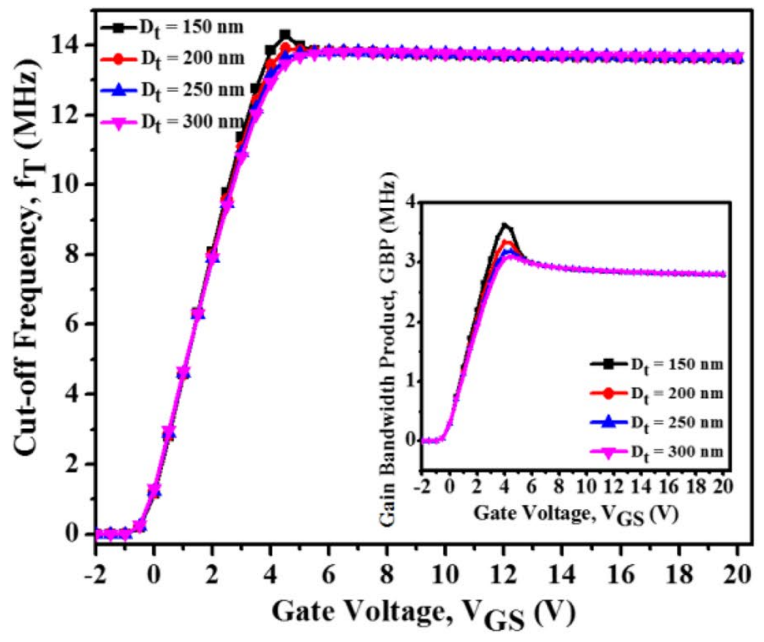

(b)

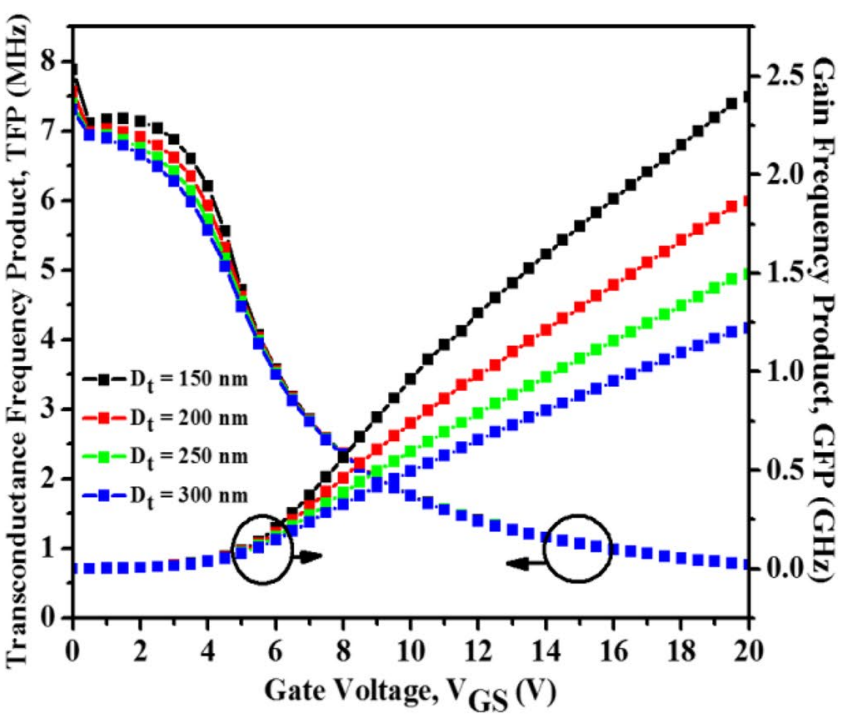

(d)

Fig. 6 a $C_{G S} \& C_{G D}$ (b) $f_{T} \&$ GBP (Inset) (c) $F_{\text {max }} \&$ GTFP (inset) (d) TFP \& GFP for different values of $D_{t}$

Table 4 Extracted parameters: $V_{t}, V_{\text {on }}, \mathrm{SS}, I_{\text {on }}, I_{\text {off }}$ depending on dielectric thickness variation

\begin{tabular}{llllllr}
\hline $\begin{array}{l}\text { Dielectric } \\
\text { Thickness }(\mathrm{nm})\end{array}$ & $\begin{array}{l}V_{t} \\
(\mathrm{~V})\end{array}$ & $V_{\text {on }}(\mathrm{V})$ & $\begin{array}{l}\text { Sub-Threshold } \\
\text { Swing (V/decade) }\end{array}$ & $\begin{array}{l}I_{\text {on }} \\
(\mathrm{A})\end{array}$ & $\begin{array}{l}I_{\text {off }} \\
(\mathrm{A})\end{array}$ & $I_{\text {on }} / I_{\text {off }}$ \\
\hline 150 & 2.21 & -0.26 & 0.22 & $1.09 \cdot 10^{-3}$ & $2.74 \cdot 10^{-14}$ & $3.98 \cdot 10^{10}$ \\
200 & 2.19 & -0.29 & 0.62 & $8.24 \cdot 10^{-4}$ & $1.72 \cdot 10^{-13}$ & $4.77 \cdot 10^{9}$ \\
250 & 2.17 & -0.32 & 0.64 & $6.61 \cdot 10^{-4}$ & $1.75 \cdot 10^{-13}$ & $3.75 \cdot 10^{9}$ \\
300 & 2.15 & -0.35 & 0.66 & $5.52 \cdot 10^{-4}$ & $4.03 \cdot 10^{-13}$ & $1.37 \cdot 10^{9}$ \\
\hline
\end{tabular}

\subsection{Impact of Temperature on the DC, Analog and RF Parameters}

In this section, impact of temperature (T) on various DC, analog and RF parameters is analyzed. In many applications like AMOLED, medical display circuits, Amorphous Oxide Semiconductor (AOS) material plays an important role. The stability and reliability of particular circuit depend on their operating temperature like most of the medical circuits need to work in the range of 300-400 K. For these 
applications, temperature stability of AOS TFT must be analyzed. Figures 7 and 8 is obtained here to see the impact of temperature changes on the different analog/RF parameters of a-ITZO TFT.

Figure 7(a) shows the variation of $I_{D S}$ with $V_{G S}$ at $V_{D S}$ $=5 \mathrm{~V}$. It is seen that drain current $\left(I_{D S}\right)$ in linear scale experience an increase of nearly $85 \%$ when temperature changes from $450 \mathrm{~K}$ to $300 \mathrm{~K}$. This trend is attributed to (a) electron and hole trapping at the interface between the material, (b) oxygen vacancies and (c) donor like defect creation in ITZO channel [39]. Out of these three, electron and hole trapping at interface will lead to degradation of drain current. Huo et al. [40] also showed the same trend in drain current and they verified their result by UPS experimental analysis which tells electron structure information. Higher UPS attributes that more electrons are trapped and less free electron availability leading to decreased electrical performance with increased temperature. The different parameters used to analyze the TFT performance are extracted from linear and log curves of transfer characteristics (Fig. 7(a)) and tabulated in Table 5. The best result is observed for $\mathrm{T}=300 \mathrm{~K}$ with $V_{\text {on }}=-0.29 \mathrm{~V}$, $I_{\text {on }} / I_{\text {off }}=4.77 \times 10^{9}$. The $I_{\text {off }}$ value is in $10^{-13}-10^{-14}$ range for all the temperature variation.

The right axis of Fig. 7(b) shows the output characteristic of a-ITZO TFT. As seen, after $V_{D S}=7 \mathrm{~V}$, the $I_{D S}$ starts to saturate. The value of $I_{D S}$ is $140 \mu \mathrm{A}, 111 \mu \mathrm{A}, 91.5 \mu \mathrm{A}$, $77.1 \mu \mathrm{A}$ for $300 \mathrm{~K}, 350 \mathrm{~K}, 400 \mathrm{~K}, 450 \mathrm{~K}$ respectively. The conduction mechanism in AOS TFT is mainly hopping but here it changes to band conduction or percolation in the conduction and $I_{D S}$ reduces as temperature increases [39]. So, trapping plays an important role for analyzing AOS TFT.

The electrical properties of device can be improved based on both the carrier concentration of active layer and interface

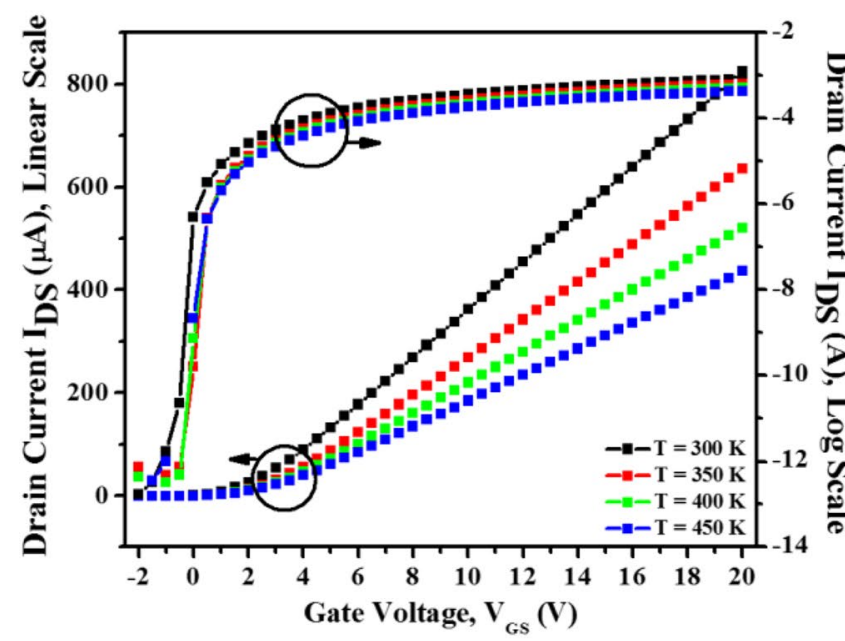

(a)

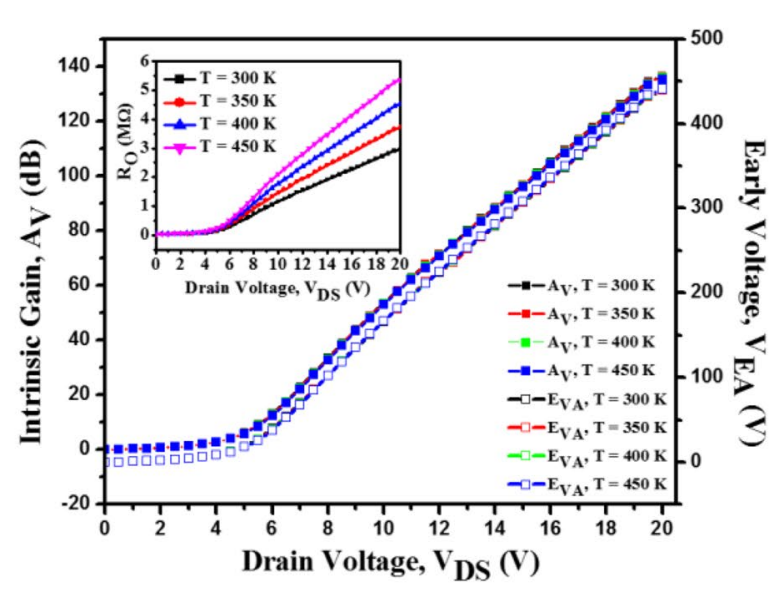

(c)

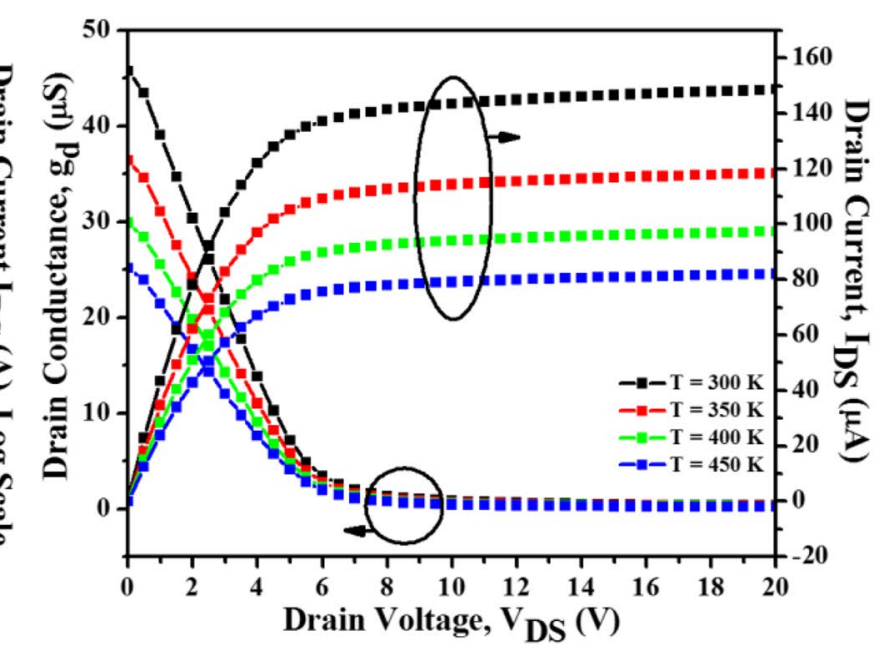

(b)

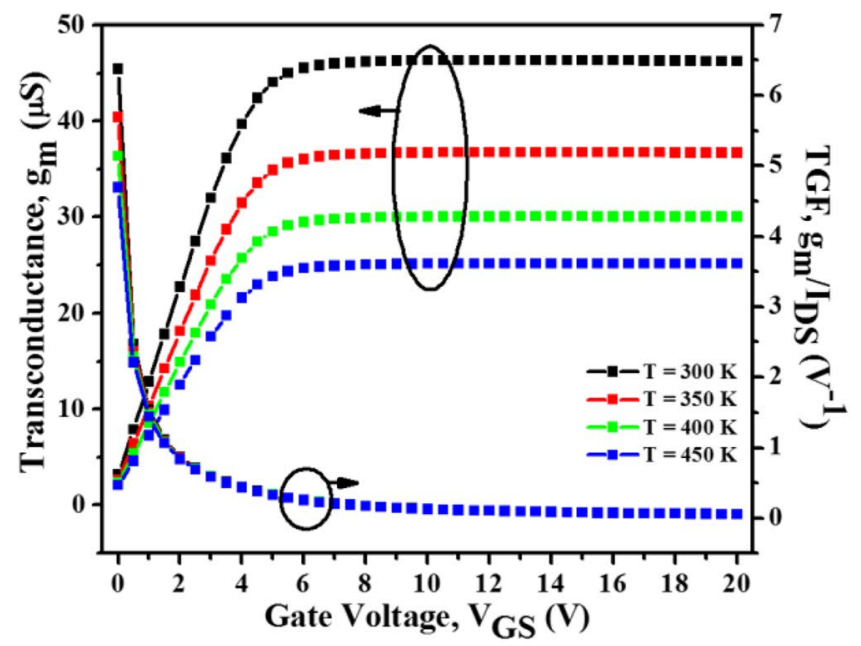

(d)

Fig. 7 a $I_{D S}$ (Linear and Log) (b) $g_{d} \&$ Output $I_{D S}$ (c) $R_{O}$ (Inset), $V_{E A}$ and $A_{V}(\mathbf{d}) g_{m} \&$ TGF for different values of T 


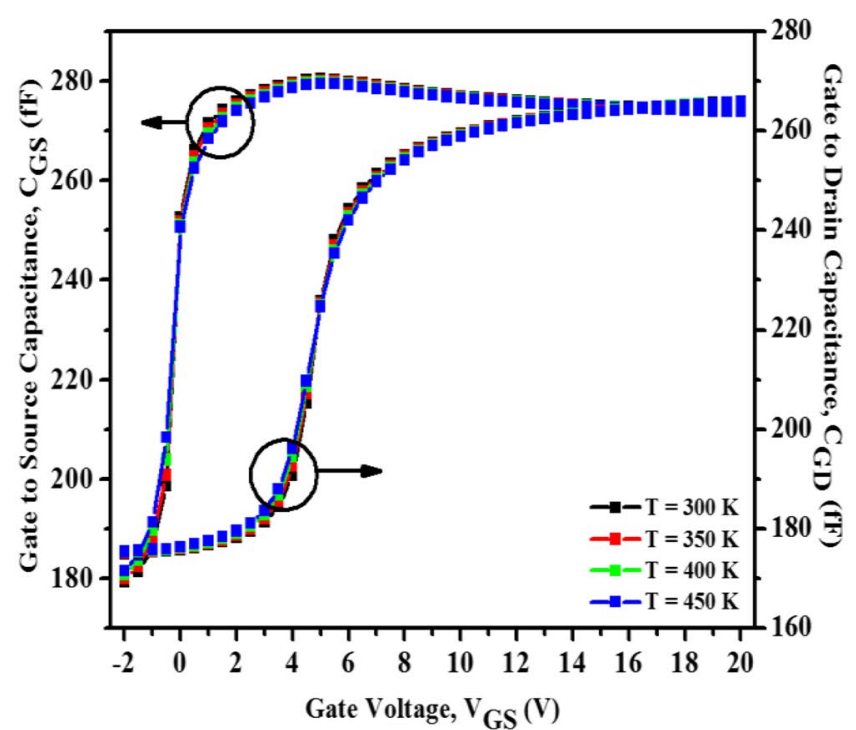

(a)

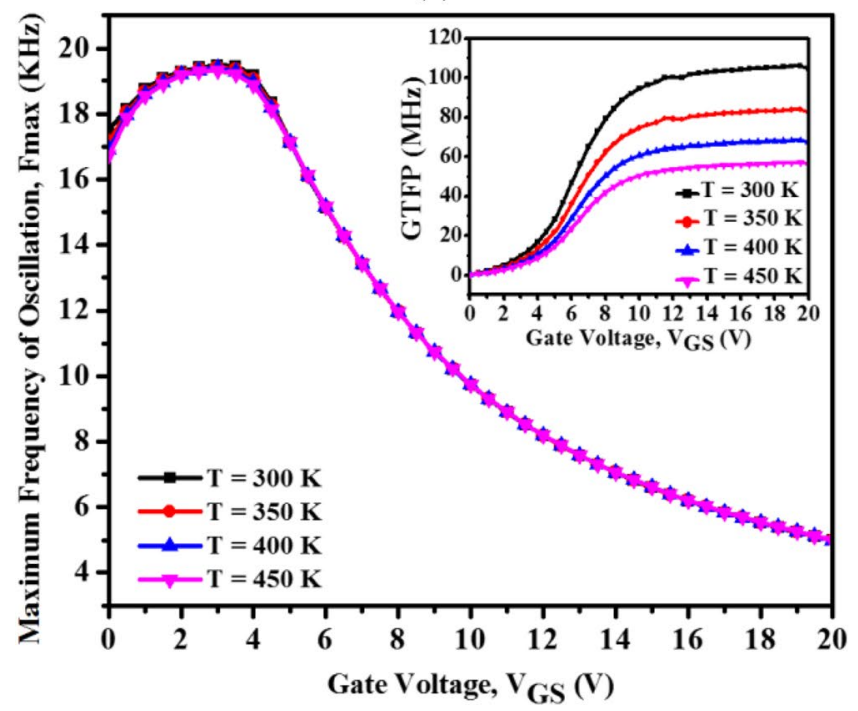

(c)

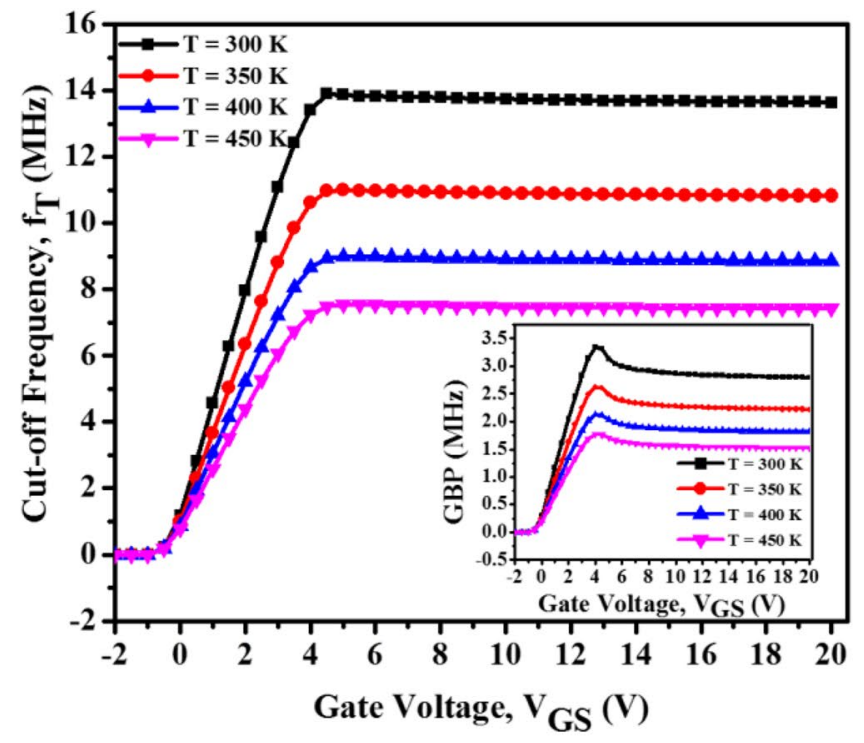

(b)

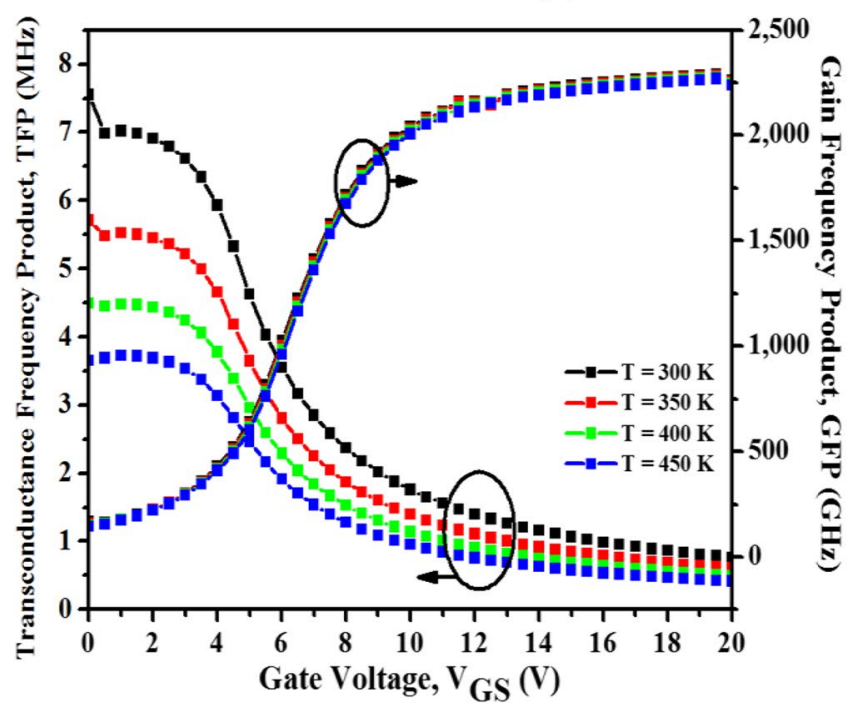

(d)

Fig. 8 a $C_{G S} \& C_{G D}$ (b) $f_{T} \&$ GBP (Inset) (c) $F_{\text {max }} \&$ GTFP (inset) (d) TFP \& GFP for different values of T

trap density. The interface trap density $\left(N_{t}\right)$ can be extracted by subthreshold slope (SS) and is given by Eq. 6 [41]:

$N_{t}=\left(\frac{S S}{\ln 10} \frac{q}{k T}-1\right) \frac{C_{o x}}{q}$ where $\mathrm{q}$ is electron charge, $\mathrm{k}$ is Boltzmann's constant, $\mathrm{T}$ is temperature and $C_{o x}$ is given by Eq. 5. From Table 5, it is seen that reduction in SS with decreasing temperature will lead to reduced $N_{t}$ and so reason of increased $I_{D S}$ at decreased temperature. The left side of the Fig. 7(b) shows
Table 5 Extracted parameters: $V_{t}, V_{o n}, \mathrm{SS}, I_{o n}, I_{o f f}$ depending on temperature variation

\begin{tabular}{llllllr}
\hline $\begin{array}{l}\text { Temperature } \\
(\mathrm{K})\end{array}$ & $\begin{array}{l}V_{t} \\
(\mathrm{~V})\end{array}$ & $V_{\text {on }}(\mathrm{V})$ & $\begin{array}{l}\text { Sub-Threshold } \\
\text { Swing }(\mathrm{V} / \mathrm{decade})\end{array}$ & $\begin{array}{l}I_{\text {on }} \\
(\mathrm{A})\end{array}$ & $\begin{array}{l}I_{\text {off }} \\
(\mathrm{A})\end{array}$ & $I_{\text {on }} / I_{\text {off }}$ \\
\hline 300 & 2.19 & -0.29 & 0.621 & $8.24 \cdot 10^{-4}$ & $1.72 \cdot 10^{-13}$ & $4.77 \cdot 10^{9}$ \\
350 & 2.18 & -0.32 & 0.662 & $6.54 \cdot 10^{-4}$ & $5.30 \cdot 10^{-14}$ & $1.23 \cdot 10^{10}$ \\
400 & 2.17 & -0.35 & 0.703 & $5.35 \cdot 10^{-4}$ & $2.03 \cdot 10^{-13}$ & $2.63 \cdot 10^{9}$ \\
450 & 2.16 & -0.38 & 0.744 & $4.48 \cdot 10^{-4}$ & $3.56 \cdot 10^{-13}$ & $1.26 \cdot 10^{9}$ \\
\hline
\end{tabular}




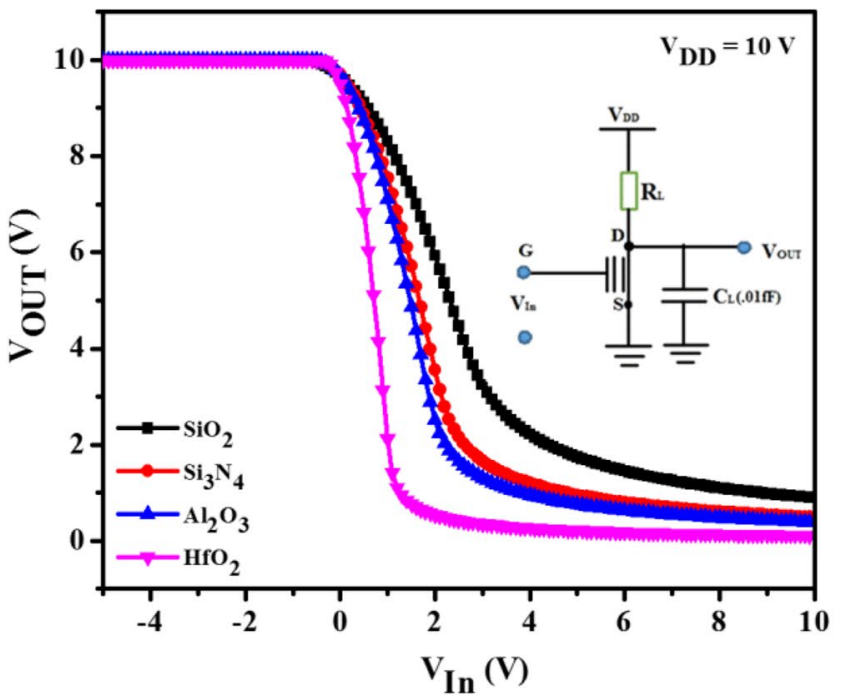

(a)

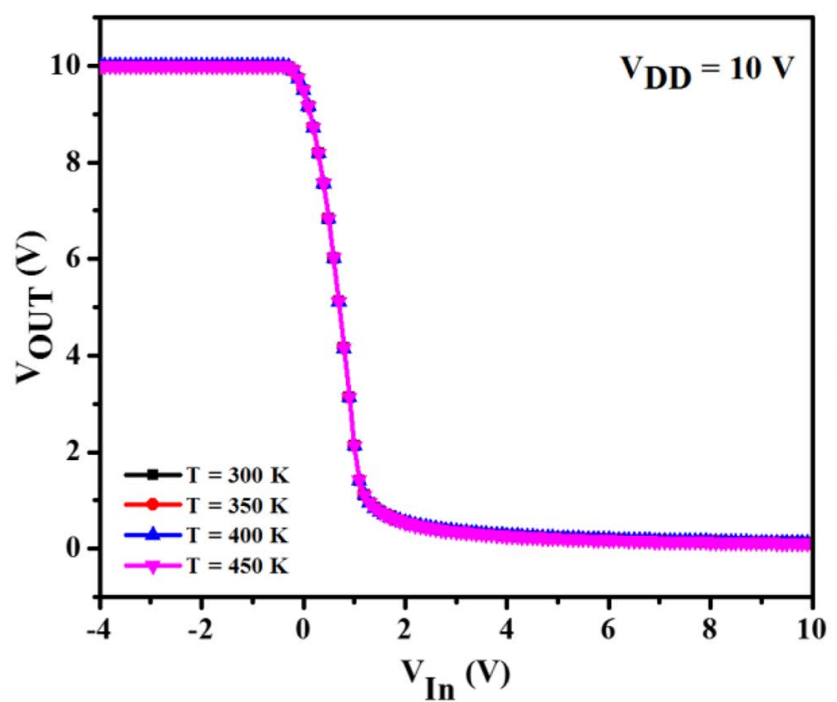

(c)

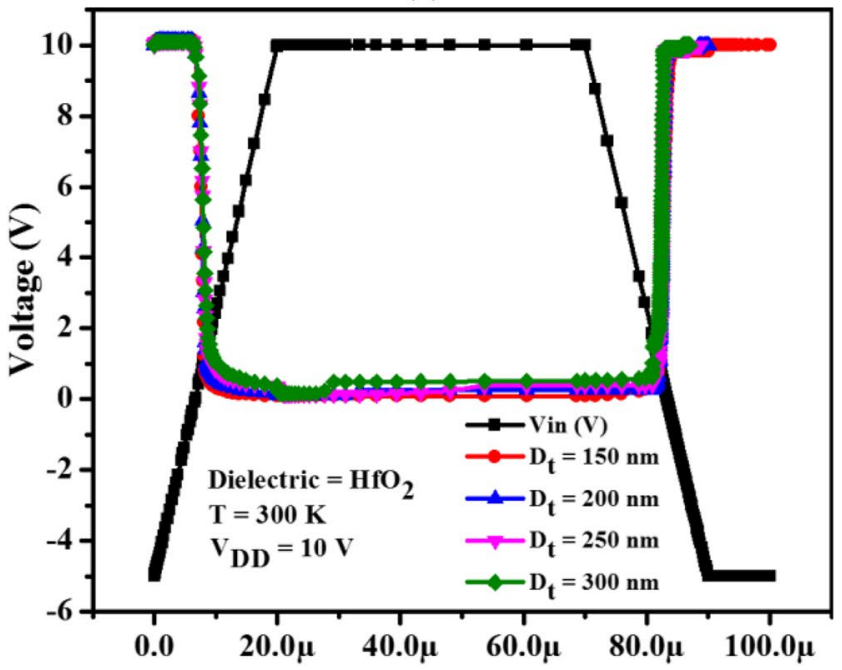

Time (s)

(e)

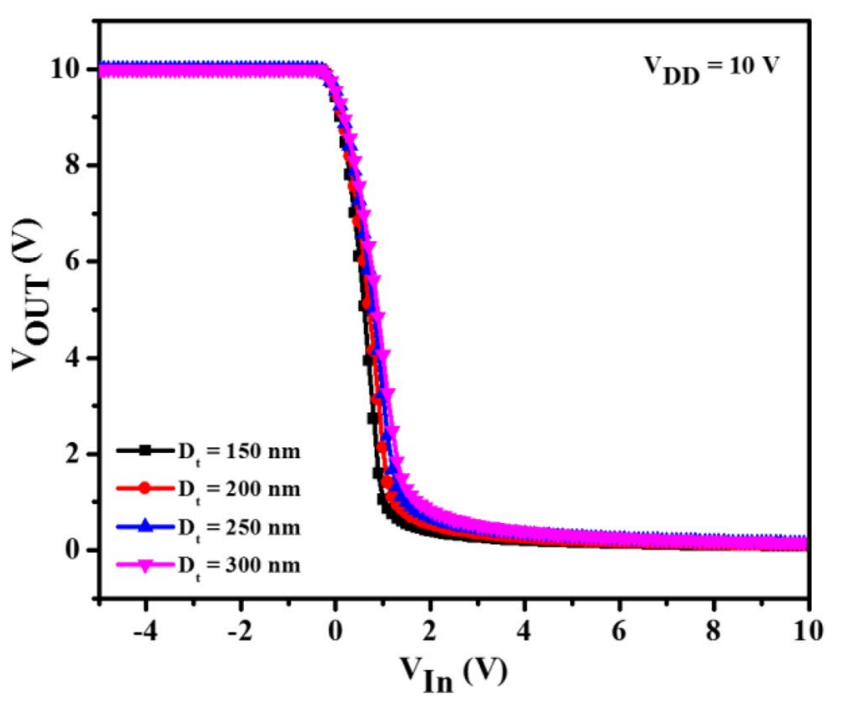

(b)

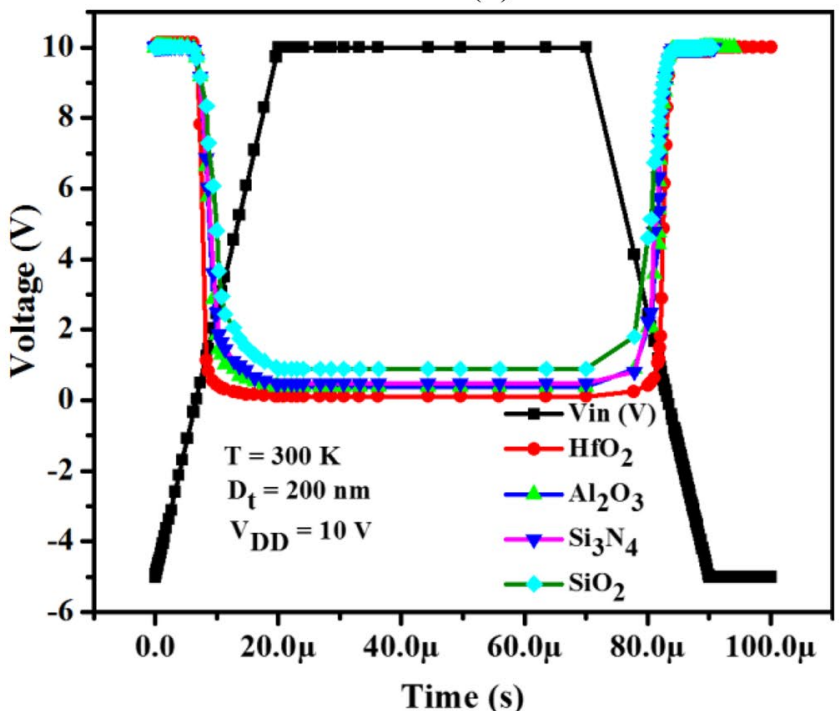

(d)

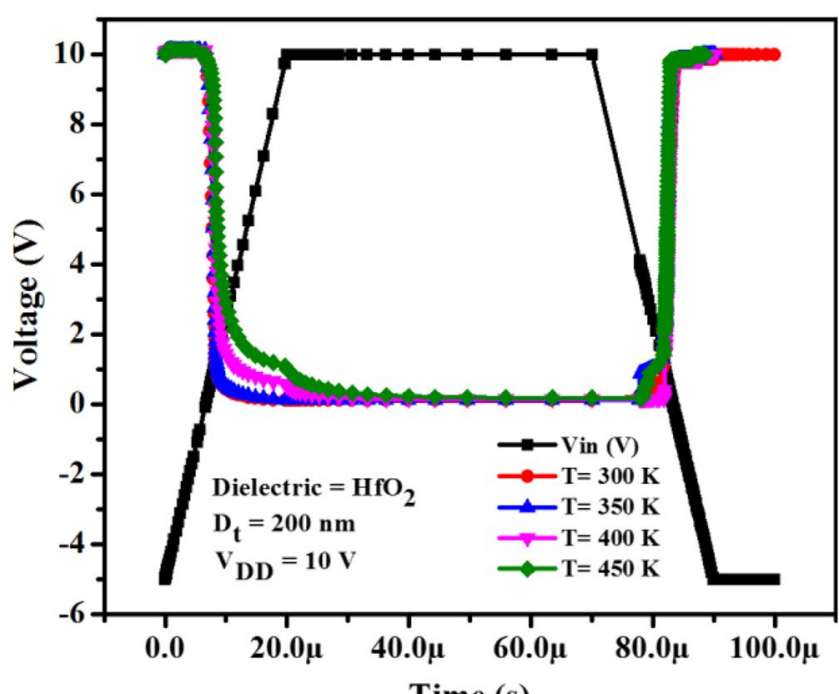

Time (s)

(f) 
4 Fig. 9 a, b and c VTC curve (d, e and f) Transient curve of the a-ITZO based resistive load inverter (inset of (a)) for different variations i.e. Dielectric Material, Dielectric thickness and Temperature respectively

the variation of drain conductance $\left(g_{D}\right)$ w.r.t $V_{D S}$. It is also decreasing by nearly $2.2 \%$ wih the increasing temperature.

Inset of Fig. 7(c) shows the variation of output resistance $\left(R_{O}\right)$ with $V_{D S} . R_{O}$ at $\mathrm{T}=450 \mathrm{~K}$ is nearly 1.8 times that of $\mathrm{T}=$ $300 \mathrm{~K} . V_{E A}$ and $A_{V}$ as seen from Fig. 7(c) shows a very little or no impact with temperature variation. From close examination we can say that analog performance is better for $\mathrm{T}=300 \mathrm{~K}$.

Figure 7(d) shows the variation of TGF and $g_{m}$ with $V_{G S}$. Both TGF and $g_{m}$ show decremented nature as we increase the temperature. The apex value of $g_{m}$ at $V_{G S}=4 \mathrm{~V}$ are $4.64 \cdot 10^{-5} \mathrm{~S}$, $3.67 \cdot 10^{-5} \mathrm{~S}, 3.00 \cdot 10^{-5} \mathrm{~S}, 2.52 \cdot 10^{-5} \mathrm{~S}$ for $\mathrm{T}=300 \mathrm{~K}, 350 \mathrm{~K}$, $400 \mathrm{~K}, 450 \mathrm{~K}$ respectively. TGF decreases nearly $35 \%$ when temperature is changed from 300 to $450 \mathrm{~K}$. The decremented nature is ascribed to decreased mobility with increase in temperature.

Figure 8(a-d) show the variation of different RF parameter with different temperature ranges. The $C_{G S} \& C_{G D}$ values as seen from the Fig. 8(a) have shown same nature for all the temperature variations. It is also seen that $C_{G S}$ is greater than that of $C_{G D}$, which can be attributed to uneven distribution of charge on application of drain source bias [42]. The highest value of $C_{G S} \& C_{G D}$ is $280 \mathrm{fF}$ and $266 \mathrm{fF}$ respectively, which is very less and beneficial for circuit designing.

The variation of $f_{T}$ with $V_{G S}$ is seen from Fig. 8(b). Nearly $85 \%$ rise is seen in $f_{T}$ when temperature is decreased from $450 \mathrm{~K}$ to $300 \mathrm{~K}$ in steps of $50 \mathrm{~K}$. The rise is result of degradation of carrier mobility with increasing temperature which in turn decreases gm [43]. GBP as seen from the inset of Fig. 8(b) has shown the same nature as that of $f_{T}$. GBP has attained peak value of $3.34 \mathrm{MHz}$ at $V_{G S}=4 \mathrm{~V}$ for $\mathrm{T}=300 \mathrm{~K}$. Figure 8(c) represent the calculation of $F_{\text {max }}$ with $V_{G S}$ for different temperature range. The peak $F_{\max }$ for all temperature variation is nearly $19.47 \mathrm{kHz}$ at $V_{G S}=3.5 \mathrm{~V}$. The measurement of GTFP with the $V_{G S}$ when swept from 0 to $20 \mathrm{~V}$ at fixed $V_{D S}$ of $5 \mathrm{~V}$ is seen from inset of Fig. 8(c). The peak value of GTFP at $V_{G S}=$ $20 \mathrm{~V}$ are $104.5 \mathrm{MHz}, 82.7 \mathrm{MHz}, 67.5 \mathrm{MHz}$ and 56.3 $\mathrm{MHz}$ for $\mathrm{T}=300 \mathrm{~K}, 350 \mathrm{~K}, 400$ and $450 \mathrm{~K}$ respectively. Figure $8(\mathrm{~d})$ is obtained to see the variation of GFP and TFP with $V_{G S}$. GFP as seen from the curve is unchanged for all temperatures. The left axis of Fig. 8(d) shows TFP at $\mathrm{T}=300 \mathrm{~K}$ is nearly 2.3 times that of TFP at $\mathrm{T}=450 \mathrm{~K}$.

\section{Application of ITZO TFT as Resistive Load Inverter}

In this section, a resistive load inverter circuit to see the application of simulated TFT at device level is implemented. As seen in inset of Fig. 9(a), a-ITZO TFT is connected with
$1 \mathrm{M} \Omega$ load resistor $\left(R_{L}\right)$ to examine clear On/Off levels in Voltage Transfer Characteristic (VTC) curve. a-ITZO TFT can be considered as variable register depending on the $V_{G S}$ values. After verifying successful resistive operation, the transistor parameter (dielectric value (high $k$ ), thickness and temperature) have been varied to observe the respective variations seen in Fig. 9(a), (b) and (c). As deduced from the Fig. 9(a, b and c), the $V_{\text {OUT }}$ of VTC is consistent with the transfer characteristics shown in Figs. 3(a), 5(a) and 7(a). It is seen that there is an improvement in VTC by changing the dielectric material to high $k\left(\mathrm{SiO}_{2}\right.$ to $\left.\mathrm{HfO}_{2}\right)$ or by decreasing the thickness of dielectric (300 $\mathrm{nm}$ to $150 \mathrm{~nm})$. This change is attributed to increase in mobility and decrease in subthreshold swing value when changing dielectric material to high $k$ or decreasing thickness. With temperature the VTC curve shows a constant behavior. The transient response of a-ITZO based inverter is also plotted in Fig. 9(d, e and f) with same parameters variation as in VTC. A ramp input of peak $10 \mathrm{~V}$ with $20 \mu$ s rise/ fall time is applied to the a-ITZO TFT inverter circuit, here also similar improvement trend is observed as in VTC. This investigation confirms the utility of simulated TFT structure for the designing of next generation logic circuits.

\section{Conclusion}

In this paper, RF and analog performance of an amorphous Indium Tin Zinc Oxide (a-ITZO) thin film transistor have been investigated. The impact of dielectric material, dielectric thickness $\left(D_{t}\right)$ and temperature $(\mathrm{T})$ on the DC, Analog and RF parameters of a-ITZO TFT have been studied in detail. The investigations suggest that high $k$ materials have potential impact on all Analog and RF parameters. $\mathrm{HfO}_{2}$ as dielectric provides best results in comparison to its low $\mathrm{K}$ dielectric siblings. Impact of $D_{t}$ on all analog and RF parameters have also been reported. Reduction of $D_{t}$ provides best results and this variation has same impact as that of using high $k$ dielectric material. It is also seen that scaling the device dimension leads to increased leakage current. Although, all the variation shows $I_{\text {off }}$ value in range of $10^{-13}$ to $10^{-14}$ which in turn provide high $I_{\text {on }} / I_{\text {off }}$. In last, the stability and reliability of a-ITZO TFT by varying temperature is investigated and it is seen that at $\mathrm{T}=300 \mathrm{~K}$, the device provides best results. This is considered as one of the FOM's of the simulated structure as most of equipment's/ devices work on ambient temperature. It is concluded that using high $k$ material which has band gap close to $\mathrm{SiO}_{2}$ or thinner dielectric at $\mathrm{T}=300 \mathrm{~K}$ gives the optimum results. Also, successful implementation of a-ITZO TFT as resistive load inverter indicates that the simulated TFT structure can provide further directions for researchers to design complex analog and RF logic circuits. 
Acknowledgements The authors are thankful to department of Electronics and Communication engineering, National Institute of Technology, Jamshedpur, India for extending Silvaco simulation facility to complete this work

Author Contributions The basic motivation to design and analyze a-ITZO TFT for Analog/RF application is of Neeraj Jain and Kunal Singh (Author $1 \& 2$ ). Shashi Kant Sharma and Renu Kumawat supervised the simulation work and conceptual discussions to develop and modify the manuscript.

Data Availability For this submission, no linked research data sets are there.

\section{Declarations}

Ethics Approval and Consent to Participate Taken Informed consent from all authors included in the study.

Consent for Publication Taken Informed consent from all authors included in the study.

Conflict of Interest The authors declare no competing interests.

Disclosure of Potential Conflicts of Interest The authors declare that they have no conflict of interest.

Research Involving Human Participants and/or Animals Not applicable.

Informed Consent Not applicable.

\section{References}

1. Business wire (2021). Dublin. https://www.businesswire.com/ news/home/2021042005736/en/Global-Thin-Film-TransistorMarket2021-to-2026---Growth-Trends-COVID-19-Impact-andForecasts---ResearchAndMarkets.com. Accessed 21 Apr 2021

2. Ji D, Jang J, Park JH, Kim D, Rim YS, Hwang DK, Noh Y-Y (2020) Recent progress in the development of backplane thin film transistors for information displays. J Inf Disp. https://doi.org/10. 1080/15980316.2020.1818641

3. Wiklund J, Karakoç A, Palko T, Yiğitler H, Ruttik K, Jäntti R, Paltakari J (2021) A review on printed electronics: fabrication methods, inks, substrates, applications and environmental impacts. J Manuf Mater Process. https://doi.org/10.3390/jmmp5030089

4. Aditya M, Rao KS (2021) Design and performance analysis of advanced MOSFET structures. Trans Electr Electron Mater. https://doi.org/10.1007/s42341-021-00338-9

5. Lu N, Jiang W, Wu Q, Geng D, Li L, Liu M (2018) A review for compact model of Thin-Film Transistors (TFTs). Micromachines. https://doi.org/10.3390/mi9110599

6. Braga JP, Lima GRD, Gozzi G, Santos LF (2018) Electrical Characterization of Thin-Film Transistors Based on SolutionProcessed Metal Oxides. Des. Simul. Construction F. Eff. Transistors. https://doi.org/10.5772/intechopen.78221

7. Saha JK, Bukke RN, Mude NN, Jang J (2020) Remarkable stability improvement of $\mathrm{ZnO}$ TFT with $\mathrm{Al} 2 \mathrm{O} 3$ gate insulator by yttrium passivation with spray pyrolysis. Nanomater. https://doi. org/10.3390/nano10050976

8. Avis C, Kim Y, Jang J (2019) Amorphous tin oxide applied to solution processed Thin-Film Transistors. Mater. https://doi.org/ 10.3390/ma12203341
9. Liu W-S, Lin Y-H, Huang C-L, Wang C-W (2017) Device performance improvement of Transparent Thin-Film Transistors with a Ti-Doped $\mathrm{GaZnO} / \mathrm{InGaZnO} / \mathrm{Ti}-\mathrm{Doped} \mathrm{GaZnO}$ sandwich composite-channel structure. IEEE Trans Electron Devices. https://doi. org/10.1109/ted.2017.2696956

10. Dargar SK, Srivastava VM (2019) Design and analysis of IGZO thin film transistor for AMOLED pixel circuit using double-gate tri active layer channel. Heliyon https://doi.org/10.1016/j.heliyon. 2019.e01452

11. Cho J, Hwang S, Ko D-H, Chung S (2019) Transparent ZnO thinfilm deposition by spray pyrolysis for high-performance metaloxide field-effect transistors. Materials. https://doi.org/10.3390/ ma12203423

12. Chung JH, Lee JY, Kim HS, Jang NW, Kim JH (2008) Effect of thickness of $\mathrm{ZnO}$ active layer on ZnO-TFT's characteristics Thin Solid Films. https://doi.org/10.1016/j.tsf.2007.07.107

13. Cheremisin AB, Kuznetsov SN, Stefanovich GB (2015) Effect of indium low doping in $\mathrm{ZnO}$ based TFTs on electrical parameters and bias stress stability. AIP Adv. https://doi.org/10.1063/1.49357 89

14. Dong J, Han D, Li H, Yu W, Zhang S, Zhang X, Wang Y (2018) Effect of $\mathrm{Al}$ doping on performance of $\mathrm{ZnO}$ thin film transistors. Appl Surf Sci. https://doi.org/10.1016/j.apsusc.2017.10.071

15. Chen Z, Han D, Zhang X et al (2019) Improving performance of Tin-Doped-Zinc-Oxide Thin-Film Transistors by optimizing channel structure. Sci Rep. https://doi.org/10.1038/ s41598-019-53766-2

16. Kara R, Mentar L, Azizi A (2020) Synthesis and characterization of $\mathrm{Mg}$-doped $\mathrm{ZnO}$ thin-films electrochemically grown on FTO substrates for optoelectronic applications. RSC Adv. https://doi. org/10.1039/d0ra06541b

17. Lee GJ, Kim J, Kim J-H, Jeong SM, Jang JE, Jeong J (2014) High performance, transparent a-IGZO TFTs on a flexible thin glass substrate. Semicond Sci Technol. https://doi.org/10.1088/0268$1242 / 29 / 3 / 035003$

18. Nomura $\mathrm{K}$, Ohta $\mathrm{H}$, Takagi A et al. Room-temperature fabrication of transparent flexible thin-film transistors using amorphous oxide semiconductors. Nature. https://doi.org/10.1038/nature03090

19. Yabuta H, Sano M, Abe K, Aiba T, Den T, Kumomi H, Hosono $\mathrm{H}$ (2006) High-mobility thin-film transistor with amorphous InGaZnO4 channel fabricated by room temperature rf-magnetron sputtering. Appl Phys Lett. https://doi.org/10.1063/1. 2353811

20. Wang D, Furuta M, Tomai S, Yano K (2020) Impact of photoexcitation on leakage current and negative bias instability in InSnZnO Thickness-Varied Thin-Film Transistors. Nanomaterials. https://doi.org/10.3390/nano10091782

21. Zhong W, Yao R, Liu Y, Lan L, Chen R (2020) Effect of SelfAssembled Monolayers (SAMs) as surface passivation on the flexible a-InSnZnO Thin-Film Transistors. IEEE Trans Electron Devices. https://doi.org/10.1109/TED.2020.3004420

22. SILVACO-TCAD (2019) ATLAS user's manual: device simulation software. SILVACO International, California

23. Seo J-H, Ling T, Gong S, Zhou W, Ma AL, Guo LJ, Ma Z (2016) Fast flexible transistors with a nanotrench structure. Sci Rep. https://doi.org/10.1038/srep24771

24. Bahubalindruni PG, Kiazadeh A, Sacchetti A, Martins J, Rovisco A, Tavares VG, Barquinha P (2016) Influence of channel length scaling on InGaZnO TFTs characteristics: unity current-gain cutoff frequency, intrinsic voltage-gain, and on-resistance. J Disp Technol. https://doi.org/10.1109/jdt.2016.2550610

25. Taouririt TE, Meftah A, Sengouga N, Adaika M, Chala S, Meftah A (2019) Effects of high-k gate dielectrics on the electrical performance and reliability of an amorphous indium-tin-zincoxide thin film transistor (a-ITZO TFT): an analytical survey. Nanoscale. https://doi.org/10.1039/c9nr03395e 
26. Martins J, Bahubalindruni P Rovisco A, Kiazadeh A, Martins R, Fortunato E, Barquinha P (2017) Bias stress and temperature impact on InGaZnO TFTs and Circuits. Materials. https://doi.org/ 10.3390/ma10060680

27. Sheng J, Han J-H, Choi W-H, Park J, Park J-S (2017) Performance and stability enhancement of $\mathrm{In}-\mathrm{Sn}-\mathrm{Zn}-\mathrm{O}$ TFTs using $\mathrm{SiO} 2$ gate dielectrics grown by low temperature atomic layer deposition. ACS Appl Mat Interfaces. https://doi.org/10.1021/acsami.7b15419

28. Kumar Singh V, Mazhari B (2012) Impact of scaling of dielectric thickness on mobility in top-contact pentacene organic thin film transistors. J Appl Phys. https://doi.org/10.1063/1.3681809

29. Vyas S, Dwivedi ADD, Dwivedi RD (2018) Effect of gate dielectric on the performance of $\mathrm{ZnO}$ based thin film transistor. Superlattice Microstruct. https://doi.org/10.1016/j.spmi.2018.05.040

30. Kim J, Rim YS, Chen H, Cao HH, Nakatsuka N, Hinton HL, Weiss PS (2015) Fabrication of High-performance ultrathin In2O3 Film Field-Effect transistors and biosensors using chemical lift-off lithography. ACS Nano. https://doi.org/10.1021/acsnano.5b01211

31. Jang J, Kim DG, Kim DM, Choi S-J, Lim J-H, Lee J-H, Kim DH (2014) Investigation on the negative bias illumination stressinduced instability of amorphous indium-tin-zinc-oxide thin film transistors. Appl Phys Lett. https://doi.org/10.1063/1.4898069

32. Hoel CA, Mason TO, Gaillard J-F, Poeppelmeier KR (2010) Transparent conducting oxides in the $\mathrm{ZnO}-\mathrm{In} 2 \mathrm{O} 3-\mathrm{SnO} 2 \mathrm{System}$. Chem Mat. https://doi.org/10.1021/cm1004592

33. Kwon J, Delker Collin J, Janes DB, Harris Charles T, Das Suprem R (2020) Molybdenum contacts to MoS2 field effect transistors: schottky barrier extraction, electrical transport and low frequency noise. Phys Status Solidi A. https://doi.org/10.1002/pssa.201900880

34. Taouririt TE, Meftah A, Sengouga N (2018) Effect of the interfacial (low-k SiO2 vs high-k Al2O3) dielectrics on the electrical performance of a-ITZO TFT. Appl Nanosci. https://doi.org/10. 1007/s13204-018-0866-x

35. Verma YK, Mishra V, Gupta SK (2020) Analog/RF and linearity distortion analysis of $\mathrm{MgZnO} / \mathrm{CdZnO}$ Quadruple-Gate Field Effect Transistor (QG-FET). Silicon. https://doi.org/10.1007/ s12633-020-00406-4
36. Pradhan KP, Mohapatra SK, Sahu PK, Behera DK (2014) Impact of high-k gate dielectric on analog and RF performance of nanoscale DG-MOSFET. Microelectron J. https://doi.org/10. 1016/j.mejo.2013.11.016

37. Adak S, Swain SK (2019) Impact of high-K dielectric materials on performance analysis of underlap In0.17Al0.83 N/GaN DG-MOSHEMTs. Nano. https://doi.org/10.1142/s179329201 9500607

38. Mallik A, Chattopadhyay A (2012) The impact of fringing field on the device performance of a p-channel tunnel field-effect transistor with a high-k gate dielectric. IEEE Trans Electron Devices. https://doi.org/10.1109/ted.2011.2173937

39. Chen, Y.-J., \& Tai, Y.-H. (2015). Hysteresis of transistor characteristics of amorphous IGZO TFTs studied by controlling measurement speed. ECS Solid State Lett. https://doi.org/10.1149/2. 0041504ssl

40. Huo C, Dai M, Hu Y, Zhang X, Wang W, Zhang H, Zhu W (2019) Temperature dependence of AOS thin film nano transistors for medical applications. Int J Nanomed. https://doi.org/10.2147/ijn. s208023

41. Liang Y, Kyungsoo J, Velumani S, Cam PTN, Junsin Y (2015) Effects of interface trap density on the electrical performance of amorphous InSnZnO thin-film transistor. J Semicond. https://doi. org/10.1088/1674-4926/36/2/024007

42. Tang Z, Wie CR (2009) Capacitance-voltage characteristics and device simulation of bias temperature stressed a-Si:H TFTs. Solid State Electron. https://doi.org/10.1016/j.sse.2009.09.025

43. Kumar B, Chaujar R (2021) TCAD temperature analysis of Gate Stack Gate All Around (GS-GAA) FinFET for improved rf and wireless performance. Silicon, https://doi.org/10.1007/ s12633-021-01040-4

Publisher's Note Springer Nature remains neutral with regard to jurisdictional claims in published maps and institutional affiliations. 